\title{
Genetic Analysis of Selected Mutants of Cowpea (Vigna unguiculata [L.] Walp) Using Simple Sequence Repeat and rcbL Markers
}

\author{
Festus Olakunle Olasupo ${ }^{1,2^{*}}$, Christopher Olumuyiwa Ilori', Esther Adekemi Stanley ${ }^{3}$, \\ Temitope Esther Owoeye ${ }^{3,4}$, David Okeh Igwe ${ }^{5,6}$ \\ ${ }^{1}$ Department of Crop Protection and Environmental Biology, University of Ibadan, Ibadan, Nigeria \\ ${ }^{2}$ Plant Breeding Section, Cocoa Research Institute of Nigeria, Ibadan, Nigeria \\ ${ }^{3}$ Bioscience Centre, International Institute of Tropical Agriculture, Ibadan, Nigeria \\ ${ }^{4}$ Department of Genomics and Bioinformatics, BIODEC, National Biotechnology Development Agency, Abuja, Nigeria \\ ${ }^{5}$ Department of Biotechnology, Ebonyi State University, Abakaliki, Nigeria \\ ${ }^{6}$ Department of Natural Sciences, Bowie State University, Bowie, MD, USA \\ Email: ^festusolasupo@gmail.com
}

How to cite this paper: Olasupo, F.O. Ilori, C.O., Stanley, E.A., Owoeye, T.E. and Igwe, D.O. (2018) Genetic Analysis of Selected Mutants of Cowpea (Vigna unguiculata [L.] Walp) Using Simple Sequence Repeat and $r c b \mathrm{~L}$ Markers. American Journal of Plant Sciences, 9, 2728-2756.

https://doi.org/10.4236/ajps.2018.913199

Received: November 25, 2018

Accepted: December 23, 2018

Published: December 26, 2018

Copyright ( 2018 by authors and Scientific Research Publishing Inc. This work is licensed under the Creative Commons Attribution International License (CC BY 4.0).

http://creativecommons.org/licenses/by/4.0/

\begin{abstract}
Genetic diversity evaluation of mutant lines is essential to facilitate their conservation and utility in breeding programs. Characterization of plant genotypes using morphological markers has limitations which make the procedure inefficient. Application of molecular tools for characterization and diversity assessment has been found useful to complement phenotypic evaluation of plant population. Therefore genetic diversity of some cowpea mutant lines was studied using simple sequence repeats (SSR) markers. DNA barcoding marker, ribulose-1,5-bisphosphate carboxylase $(r b c \mathrm{~L})$ of the chloroplast DNA (cpDNA) was also used for characterization and identification of the mutants to species level. The mean polymorphic information content (0.51) obtained from the microsatellites showed high polymorphism in accessing wide genetic diversity among the mutants and their parents. Dendrogram generated revealed 8 groups with most mutants clustered separately from their parents. Sequence analysis revealed insertions/deletions (InDels) and base substitutions as the two main classes of mutations induced in the plastid DNA of the mutants studied. The nucleotide frequencies were $26.95 \%(\mathrm{~A}), 34.43 \%(\mathrm{~T})$, $24.09 \%(\mathrm{C})$ and $14.53 \%(\mathrm{G})$. A total of $61.38 \%$ AT rich region was identified, while GC rich region was found to be $38.62 \%$. Highest rate of mutations were observed in region 3 - 4 indicating that the region is less conserved in cowpea $r b c \mathrm{~L}$ gene. The present study proved that SSR markers are useful for the genetic diversity assessment of cowpea mutants. It also proved the efficiency of $r b c \mathrm{~L}$ markers in mutants' identification. The results indicate that the mutants
\end{abstract}


are valuable genetic resources that have been developed to widen cowpea genetic base.

\section{Keywords}

Cowpea Mutants, Genetic Diversity, rbcL Gene, Sequence Analysis, InDels, Point Mutation

\section{Introduction}

Genetic diversity and phylogenetic analyses are important tools for plant breeding and genetic research because they provide information that forms the basis for conservation and utilization of genetic resources in crop improvement. Moreover, after the creation of new genetic variants by mutation induction in crop plant, genetic diversity of the mutant lines needs to be evaluated using genetic based tools and advanced molecular techniques [1] [2] [3], to facilitate their utility in cultivar development. Genetic diversity study is also important in crop breeding for the purpose of selecting genetically distant lines that are suitable for the production of heterotic hybrids [4] as well as for characterization and conservation of mutant lines.

Characterization of mutants with novel morpho-agronomic traits is fundamental to their utility in crop improvement program. Traditional characterization and selection technique depends on the application of morphological markers to reveal phenotypic variations in the plant population. However, the use of morphological markers is constrained by certain factors. It is influenced by the environments [5] [6], laborious and time consuming [7], while some morphological markers have epistatic effects [5]. DNA molecular markers are genetic markers based on individual nucleotide sequence variation, which are the direct reflection of genetic polymorphisms at the DNA level [6]. PCR-based DNA markers are efficient tools used in plant breeding and genetics to estimate very precisely the genetic diversity [8] and differentiate among genotypes at species and sub-species level. Therefore, molecular marker-base characterization has been found very useful complement to phenotypic characterization of new mutants for the purpose of crop improvement and genetic studies. Kolade et al. [9] characterized some mutant lines of cowpea using random amplified polymorphic DNAs (RAPDs) and amplified fragment length polymorphism (AFLP) markers. Their study proved the discriminatory power of AFLP over RAPDs in characterizing the mutants.

Among the PCR-based DNA molecular markers, microsatellites or simple sequence repeats (SSR) are the most frequently used markers in the genetic diversity analysis of cowpea [6] [10]-[15]. SSRs are DNA sequences with repeat lengths of a few base pairs. They provide an effective means for discriminating between genotypes [14] [16]. Research findings had revealed that SSRs are more efficient than RFLPs, RAPDs and AFLPs in level of polymorphism and informa- 
tion content in genetic diversity assessment of legumes [12] [17] [18]. Microsatellites are one of the most useful molecular markers for genetic analyses due to their co-dominant inheritance, high variability and abundance, and ease of analysis [16] [19] [20].

DNA sequence data have received a great deal of attention as a potential source of "phylogenetically informative" characters that are putatively less ambiguous than non-molecular characters [21]. Moreover, in genetic characterization of mutant lines, sequences analysis will reveal further details of the type of changes that had occurred at the nucleotides level and the precise location(s) where the mutations occurred in the plants genomes. Universal primers could be the best option when it is difficult to obtain monomorphic bands of samples' DNA required for sequence analysis from other PCR-based primers. A universal primer designed from $r b c L$ gene of chloroplast DNA (cpDNA), which encodes the large subunit of ribulose-1,5-bisphosphate carboxylase/oxygenase (RUBISCO), has been reported to be useful for the study of phylogenetic relationship of flowering plants at the species and generic level [21] [22] [23] [24] [25]. Moreover, universal primers for the amplification and sequencing of noncoding spacer between the $a t p \mathrm{~B}$ and $r b c \mathrm{~L}$ genes of cpDNA has been reported [26] which are useful for phylogenetic assessment and species level of population studies. It has also been demonstrated that $r b c \mathrm{~L}$ primers are useful for inter- and intraspecific evolutionary study of plants [22].Therefore this study was conducted to reveal and characterize the cpDNA level of variations in selected cowpea mutants and their parents.

\section{Materials and Methods}

\subsection{Plant Materials}

The 32 cowpea genotypes used in this study are listed in Table 1 . Twenty three out of the whole 32 plants were selected mutant lines induced by gamma irradiated cowpea seeds [27] [28], while only one line was a mutant induced by UVirradiated pollen of cowpea [29].

\subsection{Sample Preparation, Genomic DNA Extraction and Quantification}

Seeds of cowpea lines were planted in plastic pots filled with top soil at the roof-top garden of CPEB, University of Ibadan. Young leaf samples of these lines were harvested at four weeks after planting. Harvested leaf samples were stored in freezer at $-80^{\circ} \mathrm{C}$ and later lyophilized for 72 hours to remove the moisture content from the leaf and present the leaf in a dried form for easy grinding. Steel balls were placed in the extraction tubes and samples were punched to bits into each extraction tube. The samples were ground in a 2000 geno-grinder machine for 2 minutes at 150 strokes per minute. Genomic DNA was extracted from the thirty two leaf samples using modified method of Cetyltrimethyl ammonium bromide (CTAB) and sodium dodecyl sulphate (SDS) extraction protocol in a mini prep format [30]. Extraction buffer was added to the ground sample, 
Table 1. Cowpea genotypes used for molecular characterization.

\begin{tabular}{|c|c|c|c|c|}
\hline Genotype & Mutant phenotype & Pedigree & Mutation source & Line source \\
\hline IB & Wild type/Parental line & Cultivar & - & U.I. \\
\hline IB-ER & Non-branching erect & Mutant of IB & Gamma ray & U.I. \\
\hline IB-ER-2 & High yielding & Mutant of IB & Gamma ray & U.I. \\
\hline IB-BPC & Branched peduncle & Mutant Cultivar derived from IB & SP & U.I. \\
\hline IB-CR & Deep-green crinkled leaf & Mutant of IB & SP & U.I. \\
\hline IB-LT & Lettuce leaf & Mutant of IB-CR & Gamma ray & U.I. \\
\hline IB-CR100HT & Drought tolerant & Mutant of IB-CR & Gamma ray & U.I. \\
\hline IB-Y-1 & Yellow foliage & Mutant of IB & SP & U.I. \\
\hline IB-Y-2 & Speckle yellow foliage & Mutant of IB & SP & U.I. \\
\hline IT86D-719 & Wild type/Parental line & Elite cultivar & - & IITA \\
\hline IT-719Y & Yellow flush & Mutant of IT86D-719 & Gamma ray & U.I. \\
\hline IT-719BN-1 & Burnt leaf & Mutant of IT86D-719 & Gamma ray & U.I. \\
\hline IT-719BN-2 & Burnt leaf & Mutant of IT86D-719 & Gamma ray & U.I. \\
\hline IT-719GSLY & Small yellow foliage & Mutant of IT86D-719 & Gamma ray & U.I. \\
\hline IT-719G200BT & Drought tolerant & Mutant of IT86D-719 & Gamma ray & U.I. \\
\hline IT-719G400MS & Deep-green male sterile & Mutant of IT86D-719 & Gamma ray & U.I. \\
\hline IT-719FPL & Four primary leaves & Mutant of IT86D-719 & Gamma ray & U.I. \\
\hline IT-719G100DW & Dwarf & Mutant of IT86D-719 & Gamma ray & U.I. \\
\hline IT89KD-374-57 & Wild type/Parental line & Elite cultivar & - & IITA \\
\hline IT89KD-NL & Narrow leaf & Mutant of IT89KD-374-57 & Gamma ray & U.I. \\
\hline IT89KD-G400UF & Unifoliolate & Mutant of IT89KD-374-57 & Gamma ray & U.I. \\
\hline IT89KD-G400HT & Drought tolerant & Mutant of IT89KD-374-57 & Gamma ray & U.I. \\
\hline IT90K-284-2 & Wild type/Parental line & Elite cultivar & - & IITA \\
\hline IT90K-284FPL-2 & Four-primary leaves & Mutant of IT90K-284-2 & Gamma ray & U.I. \\
\hline IT90K-284TRV & Three-primary leaves & Mutant of IT90K-284-2 & Gamma ray & U.I. \\
\hline IT90K-UVFPL-REV & Reverted 4-primary leaves & Mutant of IT90K-284-2 & UV ray & U.I. \\
\hline IT90K-BS-1 & Big seed & Mutant of IT90K-284-2 & Gamma ray & U.I. \\
\hline IT90K-BS-2 & Big seed & Mutant of IT90K-284-2 & Gamma ray & U.I. \\
\hline IT90K-BS-3 & Big seed & Mutant of IT90K-284-2 & Gamma ray & U.I. \\
\hline IT90K-BS-4 & Big seed & Mutant of IT90K-284-2 & Gamma ray & U.I. \\
\hline IT90K-284SP & Short pod & Mutant of IT90K-284-2 & Gamma ray & U.I. \\
\hline IT90K-500EM & Early maturing & Mutant of IT90K-284-2 & Gamma ray & U.I. \\
\hline
\end{tabular}

U.I. = University of Ibadan, IITA = International Institute of Tropical Agriculture, SP = Spontaneous Mutation.

vortexed and placed on ice for $30 \mathrm{~min} .20 \%$ SDS was added to each tube and were incubated in water bath at $65^{\circ} \mathrm{C}$ for $10 \mathrm{~min}$ with continuous agitation. $5 \mathrm{M}$ sodium chloride and CTAB buffer was added to each sample and incubated at $65^{\circ} \mathrm{C}$ for $10 \mathrm{~min}$. The samples were removed from the water bath and $400 \mu \mathrm{L}$ (24:1) chloroform:isoamyl alcohol added. The sample was then centrifuged at $12,000 \mathrm{rpm}$ for $10 \mathrm{~min}$ and the supernatant transferred into new $1.2 \mathrm{~mL}$ extrac- 
tion tube and equal volume of isopropanol was added to it. This was stored at $-20^{\circ} \mathrm{C}$ for 1 hour for DNA precipitation. Samples were removed and centrifuged at 12,000 rpm for $10 \mathrm{~min}$. The supernatant was decanted and the DNA pellet was washed with $70 \%$ cold ethanol and air dried. Pellet was re-suspended in $100 \mu \mathrm{l}$ distilled water and $1.7 \mu \mathrm{l}$ RNAse was added. DNA concentration and purity was determined using Nanodrop spectrophotometer at absorbance values of $260 \mathrm{~nm}$ and $280 \mathrm{~nm}$. DNA quality was checked on $1 \%$ agarose gel electrophoresis.

\subsection{Simple Sequence Repeats (SSR) Genotyping}

DNA sample from the 28 lines and 4 parental lines was genotyped using SSR markers. Sixteen VignaSSR markers were run on the 32 samples and only markers that showed polymorphic amplification among the lines were used (Table 2). Markers that were monomorphic among lines were not informative hence were not used.

PCR was carried out in a total volume of $15 \mu$ containing $2 \mu \mathrm{l}$ of $20 \mathrm{ng}$ genomic DNA, $1.5 \mu \mathrm{l}$ of 10X PCR buffer, $1 \mu \mathrm{l}$ of $25 \mathrm{mM} \mathrm{MgCl}_{2}, 1 \mu \mathrm{l}$ of $2.5 \mathrm{mM}$ dNTPs, $0.2 \mu \mathrm{l}$ Taq polymerase (Inaqaba), $1 \mu \mathrm{l}$ of tween $20,1 \mu \mathrm{l}$ each of forward and reverse primer and $7.3 \mu \mathrm{l}$ of sterile distilled water. Amplification conditions were: an initial denaturation step of 2 mins at $94^{\circ} \mathrm{C}$, followed by 28 cycles each consisting of a denaturation step of $1 \mathrm{~min}$ at $94^{\circ} \mathrm{C}$, annealing step of $1 \mathrm{~min}$, and a final extension step of $72^{\circ} \mathrm{C}$ for 5 mins. All amplification reactions were performed using PTC-200 Peltier thermal cycler (MJ Research Inc., Watertown, MA).

\subsection{Electrophoresis of PCR Products}

Mini acrylamide gel electrophoresis was used for better resolution following the standard procedures [31] [32]. The plates were briefly treated by wiping both long and short plates with ethanol. Amplicons (amplified DNA fragments) were run on 6\% acrylamide gel electrophoresis (Acrylamide, 10XTBE, 10\% Ammonium persulfate and Temmed). The gel was allowed to polymerize and run with 0.5XTBE buffer ( $45 \mathrm{mMTris}$-acetate, $5 \mathrm{mM}$ Boric acid, and $1 \mathrm{mM}$ EDTA, $\mathrm{pH}$

Table 2. List of SSR markers used in the study.

\begin{tabular}{cc}
\hline Marker & Primer Sequence 5’-3' \\
\hline VM34_F & AGCTCCCCTAACCTGAAT \\
VM34_R & TAACCCAATAATAAGACACAT \\
VM37_F & TGTCCGCGTTCTATAAAT \\
VM37_R & CGAGGATGAAGTAACAGA \\
VM54_F & CACACACACACATAGATA \\
VM54_R & TCCATCACTGATCACCTGTT \\
VM57_F & GGAAGGGGTAGAGGAAAAGTGAA \\
VM57_R & TGATGATGATGGGTGAATGAGTTG
\end{tabular}


8.0) at $100 \mathrm{~V}$ for 1 hour. $100 \mathrm{bp}$ ladder was used as a molecular size standard. Gels were visualized by staining with ethidium bromide solution $(0.5 \mu \mathrm{g} / \mathrm{ml})$ and banding patterns were photographed over UV light using UVP-computerized gel photo documentation system.

\subsection{Sequencing Reaction and Analysis}

The SSR markers used in the diversity study were all polymorphic and could not be used for sequencing. Therefore, the following pair of $r b c L$ primer was used for the sequence:

H535-5'CTTTCCAAGGCCCGCCTCA3' for forward sequence;

C705-5'CATCATCTTTGGTAAAATCAAGTCCA3' for reverse sequence.

\subsection{Cocktail Mix and Condition for the PCR}

Genomic DNA was subjected to the following cocktail mix: $1.0 \mu \mathrm{L}$ of $10 \times$ PCR buffer, $1.0 \mu \mathrm{L}$ of $25 \mathrm{mM} \mathrm{MgCl}_{2}, 0.5 \mu \mathrm{L}$ of $5 \mathrm{pMol}$ forward primer (H535), $0.5 \mu \mathrm{L}$ of 5 pMol reverse primer (C705), 1.0 $\mu \mathrm{L}$ DMSO (Dimethyl sulfoxide), $0.8 \mu \mathrm{L}$ of $2.5 \mathrm{mM}$ DNTPs, $0.1 \mu \mathrm{L}$ of $5 \mathrm{ug} / \mu \mathrm{L}$ Taq polymerase (Thermoscientific), $2.0 \mu \mathrm{L}$ of $10 \mathrm{ng} / \mu \mathrm{L}$ of genomic DNA and $3.1 \mu \mathrm{L}$ of water. PCR was carried out in a total volume of $10 \mu \mathrm{L}$ containing $20 \mathrm{ng}$ of genomic DNA. Amplification reactions were performed with Veriti 96 well thermal cycler (Applied Biosystems) using the following conditions: an initial denaturation step of $5 \mathrm{~min}$ at $94^{\circ} \mathrm{C}$, followed by 36 cycles each consisting of a denaturation step of $30 \mathrm{sec}$ at $94^{\circ} \mathrm{C}$, annealing step of $30 \mathrm{sec}$ at $56^{\circ} \mathrm{C}$, extension temperature of $72^{\circ} \mathrm{C}$ for $45 \mathrm{sec}$, a final extension step of $72^{\circ} \mathrm{C}$ for $7 \mathrm{~min}$ and a hold temperature of $10^{\circ} \mathrm{C}$. The PCR product (amplicon) was loaded on $1.5 \%$ Agarose to check the amplification, after which the amplicon was purified.

\subsection{PCR Purification}

The PCR product was purified by adding 2 volume $(20 \mu \mathrm{L})$ of absolute ethanol. It was incubated at room temperature for 15 minutes, spun down at 10,000 rpm for 15 minutes and the supernatant was decanted. Then $100 \mu \mathrm{L}$ of $70 \%$ ethanol was added, the mixture was votexed and spun down at 10,000 revolutions per minute (rpm) for 15 minutes. The supernatant was decanted and PCR product was air dried. $20 \mu \mathrm{L}$ of DNAse and RNAse free $\mathrm{H}_{2} \mathrm{O}$ was added and the product was checked again on $1.5 \%$ agarose.

\subsection{Sequencing Reaction}

The reactions for 96-well reaction plates (microcentrifuge tubes) was prepared by adding the following reagents to a separate tube: $4.0 \mu \mathrm{L}$ of $2.5 \mathrm{X}$ terminator ready reaction mix, $2.0 \mu \mathrm{L}$ of $5 \mathrm{X}$ Bigdye Sequencing Buffer (BigDye Terminator v3.1), 3.2 pmol primer, $20 \mathrm{ng}$ PCR product and deionized water was added to make a total volume of $20 \mu \mathrm{L}$. It was mixed well and spun down briefly. The sample was loaded on the Veriti 96 well thermal cycler (Applied Biosystems). 
The tubes were placed in a thermal cycler and set to the correct volume. Initial denaturation step of rapid thermal ramp to $96^{\circ} \mathrm{C}$ for $1 \mathrm{~min}$ was performed. This was followed by 25 cycles each consisting of a denaturation step of $10 \mathrm{sec}$ at $96^{\circ} \mathrm{C}$, annealing step of $5 \mathrm{sec}$ at $50^{\circ} \mathrm{C}$, extension temperature of $60^{\circ} \mathrm{C}$ for $4 \mathrm{~min}$, a hold temperature of $4^{\circ} \mathrm{C}$ and the contents of the tubes in a microcentrifuge were spin down.

\subsection{Purification of Sequencing Product}

To the PCR product in the 96-well reaction plate, $5 \mu \mathrm{L} 125 \mathrm{mM}$ EDTA was added. This was followed by the addition of $60 \mu \mathrm{L}$ of $100 \%$ ethanol to each well to each well. The plate was sealed with plate septa, mixed by inverting 4 times and incubated at room temperature for 15 minutes. The plate was spin down at $3000 \mathrm{rpm}$ for 45 minutes at $4^{\circ} \mathrm{C}$. The plate was inverted and it was spin up to $900 \mathrm{rpm}$. To each well, $60 \mu \mathrm{L}$ of $70 \%$ ethanol was added and centrifuge at $3000 \mathrm{rpm}$ for 15 min. The plate was inverted and it was spin up to $900 \mathrm{rpm}$ for 1 minute and the samples were re-suspended in injection buffer i.e. HID Formamide (Applied Biosystems).

\subsection{Data Scoring and Statistical Analysis}

Microsatellite markers were scored as follows:

$>1$ for present alleles.

0 for absent alleles.

9 for missing data.

The polymorphic information content (PIC); that is the level of polymorphism shown by each SSR marker for distinguishing cowpea lines, was determined following the procedures of Powell et al. [16] and Weir [33]:

$$
H_{e}=1-\sum P_{i}^{2}
$$

where, $H_{e}$ is the expected heterozygosity or PIC and $P_{i}$ is the frequency of the ith allele.

Each SSR fragment was treated as binary matrix in which band presence was coded as 1 for present and 0 for absent. Based on the binary matrix, Euclidean dissimilarity index was computed. Subsequently, using neighbor joining clustering algorithm, a dendogram was generated with the unweighted pair group method using arithmetic average (UPGMA) algorithm of DARwin 5.0.158 software [34] [35].

The samples were loaded on 3130xl Genetic Analyzer in order to generate sequence data. DNA sequences were edited and analyzed using BioEdit and MEGA software. Phylogenetic analyses were conducted in MEGA5 [36].

\section{Results}

\subsection{Genetic Diversity Assessment}

Four primers (Vm34, Vm37, Vm54 and Vm57) out of the sixteen SSR primers screened for the molecular study revealed polymorphic loci (Figure 1) while 


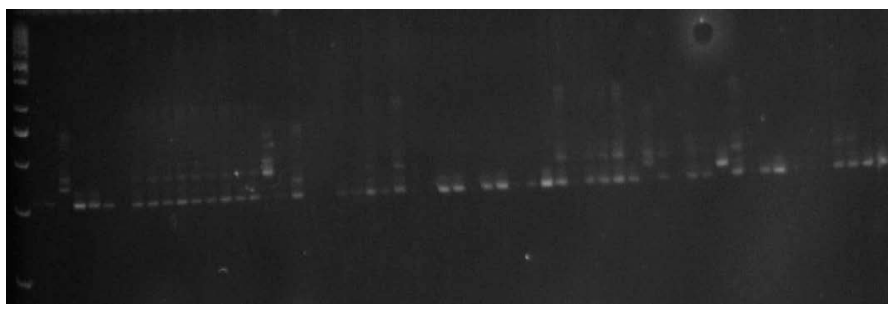

(a)

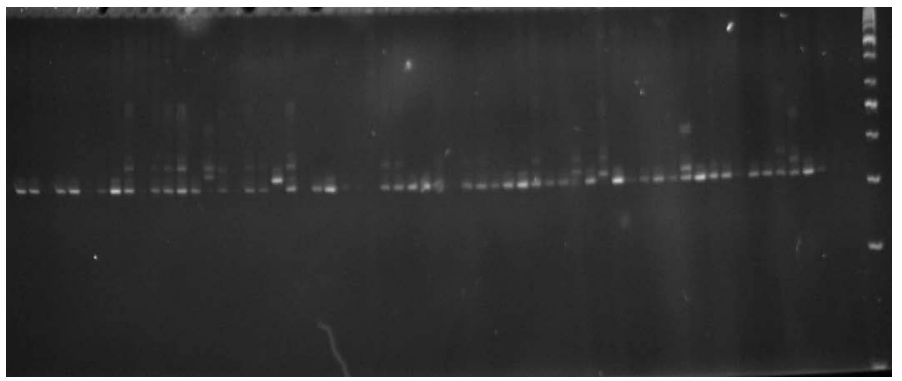

(b)

Figure 1. The picture from $6 \%$ acryl amide gel showing polymorphic bands of amplified primers; (a) polymorphic bands from primer Vm34, (b) polymorphic bands from primer Vm57.

monomorphism were observed with the other twelve primers. The polymorphic markers were used to evaluate the genetic diversity of 32 cowpea lines. A total of 15 alleles were produced on these four loci with an average of 3.75 alleles per SSR locus (Table 3). The primer, Vm57 revealed the highest diversity index among all the lines and the polymorphic information content (PIC) varied from 0.33 to 0.63 with a mean of 0.51 .

The dendrogram generated by UPGMA method showed the genetic relationship among cowpea lines (Figure 2). Seven distinct branches were revealed in the phylogenetic analysis of all the mutant lines including their parents. Comparing the clustering of the mutants with their parents, only IB-ER and IB-ER-2 were observed in the same cluster (Group I) together with their parent IB, while other mutant derivatives of IB clustered in group VI and VII. IT90K-284-2 clustered with its mutant lines IT90K-BS-4, IT90K-500EM, IT90K-284TRV, IT90K-BS-3 and IT90K-284FPL-2 in group I, while it's other mutant derivatives clustered in group II and IV. IT86D-719 was observed in cluster IV, while its mutant derivatives clustered with group I, III, V and VI. IT89KD-374-57 was observed in cluster IV, while other mutant derived from it clustered with group I and II. These results show that the mutants were diverse in their genetic makeup from their parental lines.

\subsection{Sequence Analysis}

The sequence alignments of cowpea mutant lines and their parents with the $r b c \mathrm{~L}$ reference sequence are presented in Figure 3. As a result of mutagenic treatment of cowpea lines with gamma rays, insertion of $\mathrm{T}$ and $\mathrm{G}$ was observed in the $r b c \mathrm{~L}$ 
Table 3. Summary statistics of SSR markers used in cowpea mutants' characterization.

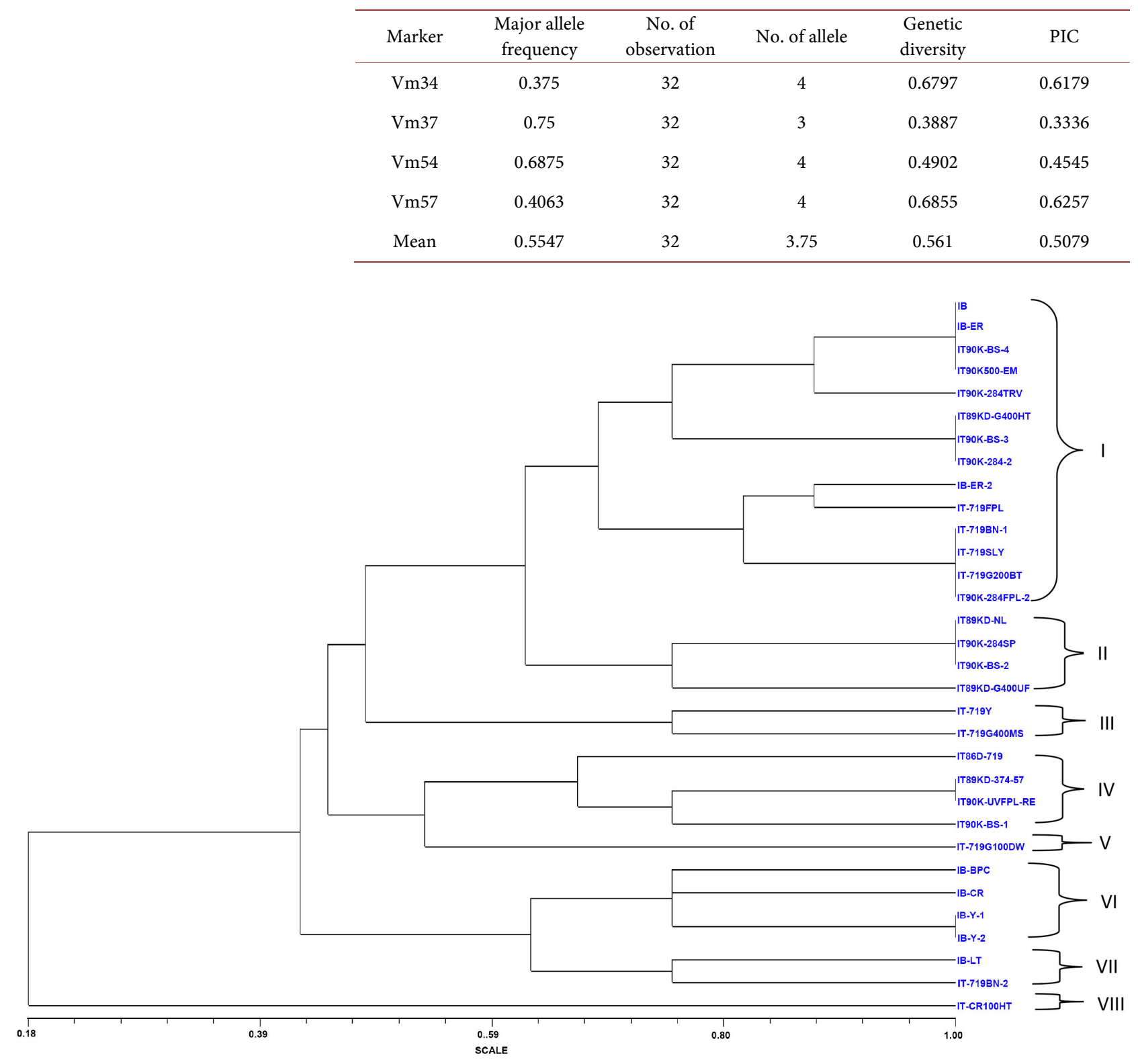

Figure 2. Dendrogram showing genetic diversity between the parents and mutant cowpea lines.

regions 2 and 3, respectively of IB-ER when compared with its parent IB, while $\mathrm{G}$ was substituted for $\mathrm{A}$ at region 4 of the sequence. A was deleted in IB-ER at position 129 of its sequence when compared with IB sequence. In IB-LT, insertion of AT was observed at positions $1-2$, while base substitutions of $\mathrm{T}$ for $\mathrm{G}$ at region 3 and $\mathrm{G}$ for $\mathrm{A}$ at position 4 of its parent IB-CR sequence. In addition to these, deletion of 5 bases (AATTC) in IB-LT was observed at position 128 to 132 when compared with IB-CR. The sequence data also revealed the type of changes that occurred in the $r b c \mathrm{~L}$ region of IB line as a result of spontaneous mutations that produced IB-BPC, IB-CR, IB-Y-1 and IB-Y-2. There was deletion of G and $A$ at regions 4 and 129, respectively in IB-BPC. In IB-CR insertion of T and TTC 


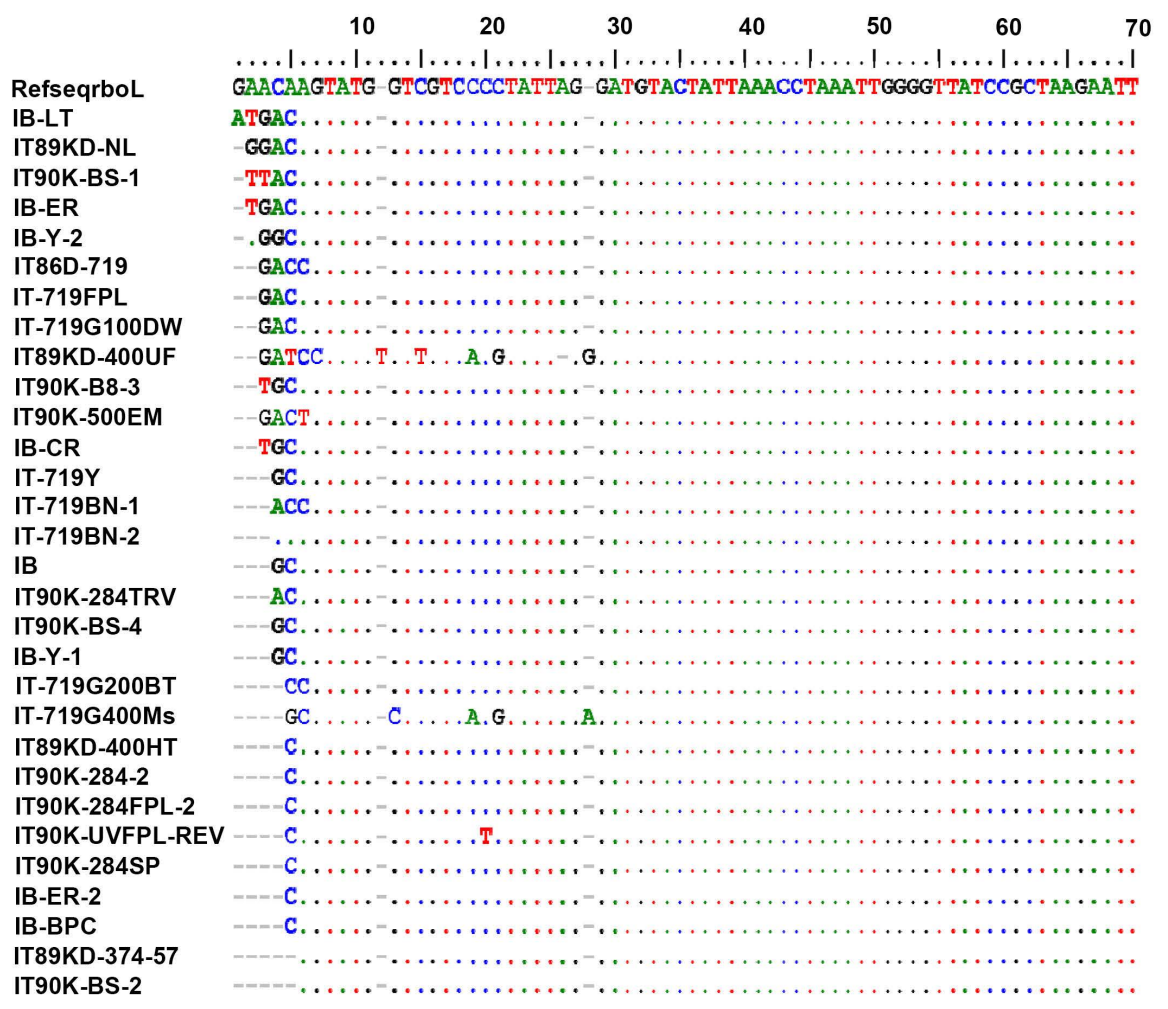

Figure 3. $r b c L$ sequence alignment of cowpea mutants with their parents.

was observed at positions 3 and 130 - 133, respectively. Deletion of A was observed at position 129 in IB-Y-1, while in IB-Y-2 there was insertion of G at position 3 and deletion of $A$ at position 129.

From the $r b c \mathrm{~L}$ sequence data there were variations in the effects of mutagenic treatment of IT86D-719 with gamma rays on the resultant mutants in this study. In mutant line IT-719BN-1, G and A nucleotides were deleted at positions 3 . There was a deletion of $\mathrm{G}$ at position 3, while ACC bases were substituted for CAA at region 4 - 6 in IT-719BN-2. In IT-719FPL and IT-719G100DW, C was substituted for A at region 6 of the sequences. At regions 3 - 4 of IT-719G200BT, GA was deleted. In IT-719G400MS, GA was deleted at region 3 - 4, substitutions of $\mathrm{C}$ for $\mathrm{G}, \mathrm{G}$ for $\mathrm{C}, \mathrm{C}$ for $\mathrm{A}$ and $\mathrm{C}$ for $\mathrm{G}$ were respectively, observed at regions 5, 13, 19 and 21 and insertions of $\mathrm{A}$ was revealed at regions 28. However, in IT-719Y, G was deleted at region 3, while A and C were respectively, substituted for $\mathrm{G}$ and $\mathrm{A}$ at regions 4 and 6 .

The mutants derived from IT89KD-374-57 were different from their parent with respect to $r b c \mathrm{~L}$ sequence. There was an insertion of $\mathrm{C}$ at position 5 of IT89KD-400HT. In IT89KD-400UF, the sequence data revealed insertions of GAT, T and G at positions $3-5,12$ and 28 respectively, while A, G, C, C and C were respectively, substituted for $\mathrm{C}, \mathrm{C}, \mathrm{T}, \mathrm{A}$ and $\mathrm{G}$ at positions $6,7,15,19$ and 21. Insertion of four bases (GGAC) was observed at position 2 - 5 of IT86KD-NL.

The $r b c \mathrm{~L}$ sequence data shows various changes that occurred in the mutants produced from gamma irradiation of IT90K-284-2 line. In IT90K-284TRV, there 
was insertion of A at positions 4. In IT90K-500EM, there were insertions of GA and $\mathrm{T}$ at positions 3 - 4 and 6 respectively. In IT90K-BS-1, insertion of TTA bases was observed at position 2 - 4, while there was deletion of $\mathrm{C}$ and insertion of $\mathrm{A}$ in IT90K-BS-2 at position 5. TG was respectively, inserted to region 3 - 4 in IT90K-BS-3, while there was only an insertion of G to region 4 in IT90K-BS- 4. IT90K-UVFPL-REV was a four-primary leaf mutant derived from the UV treatment of pollen prior to pollination in IT90K-284-2. In this mutant, a base substitution of $\mathrm{C}$ for $\mathrm{T}$ was observed at region 20 . When compared with other regions of the $r b c \mathrm{~L}$ sequences, high mutation rates were observed between regions 2 - 6 of all samples studied with regions $3-4$ being the highest mutable sites.

Analysis of the $r b c L$ sequence of the mutants shows the presence of InDels and point mutations (base substitutions) as the two main classes of mutations induced in the plastid DNA of the mutants studied. Only one stable UV induced mutant plant was included in the sequence analysis, hence the type of mutation induced from the UV source could not be quantified by the sequence results. Also, the rates of different transitional substitutions are shown in bold and those of transversional substitutions are shown in italics (Table 4). The nucleotide frequencies were $26.95 \%(\mathrm{~A}), 34.43 \%(\mathrm{~T}), 24.09 \%(\mathrm{C})$, and $14.53 \%(\mathrm{G})$. A total of $61.38 \%$ AT rich region was identified, while GC rich region was found to be $38.62 \%$. The analysis involved 30 nucleotide sequences. Codon positions included were $1^{\text {st }}+2^{\text {nd }}+3^{\text {rd }}+$ Noncoding. All ambiguous positions were removed for each sequence pair. There were a total of 134 positions in the final dataset. Observations on the positions towards the end of the sequence alignments were not accounted for in this report because they could not be justified.

\subsection{Molecular Phylogenetic Analysis of the Mutants}

The estimated genetic divergence among the sequences of cowpea were obtained using rbcL gene (Table S1). Phylogenetic reconstruction of the mutant lines including the parents was inferred using the Maximum Likelihood method based on the Kimura 2-parameter model [35]. The bootstrap consensus tree inferred from 1000 replicates is taken to represent the evolutionary history of the taxa analyzed [36]. Branches corresponding to partitions reproduced in less than $50 \%$ bootstrap replicates are collapsed. The percentage of replicate trees in which the associated taxa clustered together in the bootstrap test (1000 replicates) is shown above the branches. Initial tree(s) for the heuristic search were obtained automatically by applying Neighbor-Join and BioNJ algorithms to a matrix of pairwise distances estimated using the Maximum Composite Likelihood (MCL) approach, and then selecting the topology with superior log likelihood value. The rate variation model allowed for some sites to be evolutionarily invariable $\left([+I, 0.0000 \%\right.$ sites $)$. Codon positions included were $1^{\text {st }}+2^{\text {nd }}+3^{\text {rd }}+$ Noncoding. All positions with less than $95 \%$ site coverage were eliminated. That is, fewer than $5 \%$ alignment gaps, missing data, and ambiguous bases were allowed at any 
Table 4. Maximum composite likelihood estimate of the pattern of nucleotide substitution.

\begin{tabular}{ccccc}
\hline & $\mathrm{A}$ & $\mathrm{T}$ & $\mathrm{C}$ & $\mathrm{G}$ \\
\hline $\mathrm{A}$ & - & 11.45 & 4.83 & 7.6 \\
$\mathrm{~T}$ & 8.96 & - & 5.16 & 8.01 \\
$\mathrm{C}$ & 8.96 & 12.23 & - & 8.01 \\
$\mathrm{G}$ & 8.5 & 11.45 & 4.83 & - \\
\hline
\end{tabular}

NOTE: Each entry shows the probability of substitution (r) from one base (row) to another base (column). For simplicity, the sum of $r$ values is made equal to 100 .

position. The evolutionary history was inferred using the UPGMA method [37]. The optimal tree is shown in Figure 4. The percentage of replicate trees in which the associated taxa clustered together in the bootstrap test (1000 replicates) is shown above the branches [38]. The phylogenetic distances were computed using the Kimura 2-parameter method [39] and are in the units of the number of base substitutions per site. The analysis involved 32 nucleotide sequences. Codon positions included were $1^{\text {st }}+2^{\text {nd }}+3^{\text {rd }}+$ Noncoding. All ambiguous positions were removed for each sequence pair. There were a total of 1164 positions in the final dataset.

Four main cluster groups of cowpea lines were revealed from the phylogenetic tree (Figure 4). The number of genotypes grouped within cluster I, II, III and IV was 1, 23, 4 and 2, respectively (excluding 2 samples with bad sequence data). The grouping which was irrespective of the mutant origin indicated that similarity within the mutant populations was independent of the $r b c \mathrm{~L}$ sequence data. The $r b c \mathrm{~L}$ reference sequence retrieved from NCBI database was included in the computation and it was found within cluster II, while the GU140278_COI gene sequence from a different organism that is not related to cowpea was usedas an out-group which confirmed the validity of these results. The result indicates that IB is similar to its mutant derivatives except IB-CR which was differentiated into cluster I. IT86D-719 is different from all its mutant lines except IT-719G200BT, IT-719BN-1 and IT-719G400MS. IT89KD-374-57 is similar to all its mutant lines except IT89KD-400UF, while IT90K-284-2 is different from IT90K-500EM only.

\section{Discussion}

Molecular characterization has gradually replaced phenotypic evaluation among plants and animals species since the evolution of gene theory. PCR-based DNA markers are very valuable tools to plant geneticists and breeders because they are useful for precise estimates of genetic diversity. The SSR markers used in this study were able to separate each of the parental lines from most of their mutant derivatives. Some DNA changes resulting from mutation events led to the variations detected by microsatellites between the mutants and their parents in this study. Hamzekhanlu et al. [2] had reported that polymorphic amplification 


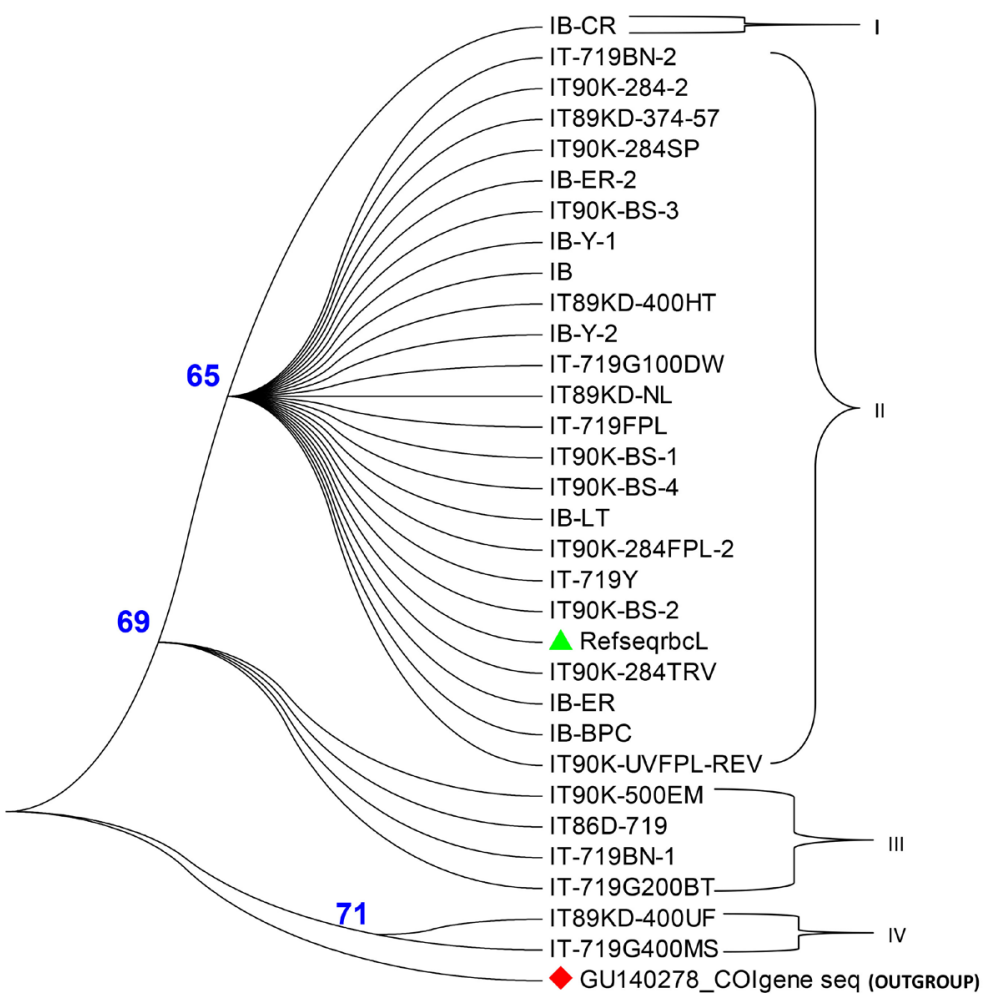

Figure 4. A Phylogeny of $r b c L$ gene in cowpea mutants inferred by using the Maximum Likelihood method based on the Kimura 2-parameter model and the percentage of trees in which the associated taxa clustered together is shown above the branches.

products which represent one allele per locus can result from changes in either the sequence of the primer binding site, such as point mutations, or from changes altering the size or preventing successful amplification of a target DNA such as insertions, deletions, and inversions. Mutations resulting in polymorphisms are those occurring on primer binding sites, leading to an increase or decrease in the total number of primer binding sites, and consequently the number of amplified fragments [2]. Furthermore, some changes in the genome of the mutants were responsible for the differences observed in the clustering of most mutants from their parents in the dendrogram constructed from SSR markers. Although the clustering patterns of these mutants are not correlated with their phenotypic traits (morphology), further investigations may be needed to know if they could infer useful agronomic traits inherent in the mutants. The genetic diversity assessment presented in this study demonstrates that SSR marker could be used for molecular characterization of cowpea mutant lines. Selected cowpea mutants in this study were genetically diverse from their parents indicating that they are valuable genetic resources to be added to cowpea genepool.

The effects of any gene mutation on an organism will vary depending upon the functional region of the gene (promoter, intron, coding, or 3' untranslated regions) where the mutation occurs, and whether the function of an essential 
protein has been altered [40]. The effect of mutations on the function of a gene will be determined by the type of changes that has occurred in the nucleotide sequence. Generally, mutations are classified based on the type and the extent of molecular changes in the nucleic acid affected by mutational event. Analysis of the $r b c \mathrm{~L}$ sequence of the mutants shows the presence of insertions and deletions (InDels) and point mutations (base substitutions) as the two main classes of mutations induced in the plastid DNA of the mutants studied. Of all the mutations observed, InDels are more predominant mutations in this study. This is expected because most of the mutants studied were induced by gamma irradiation. Brown [41] listed some negative consequences of ionizing radiation overdoses such as deletions of DNA nucleotide sequences that may cause reading-frame shifts, inactive protein products, or faulty transcripts. These may have accounted for a wide range of morphological variations observed in among the mutants reported in Olasupo et al. [28]. The relatively higher rate of transitional substitution range $(5.16-12.23)$ as compared to the rate of transversion range (4.83 - 11.45) among the mutants studied corroborates the report of Lee et al. [40] that transitions occur more frequently than transversions in mutational events. The higher percentage of AT rich region than GC rich region observed in this study indicates that there is a bias towards AT in the substitutional rate with regards to A, T, G and C. Yamane et al. [42] reported that the AT-richness of chloroplast DNA influences both the distribution of InDels and dynamics of nucleotide substitution. The highest rate of mutations observed in region $3-4$ also indicates that the region is less conserved in cowpea $r b c \mathrm{~L}$ gene.

The four groups obtained from the phylogenetic tree which is irrespective of the mutant origin indicated that similarity within the mutant populations is independent of the $r b c \mathrm{~L}$ sequence data. The clustering together of parental lines and their respective mutant derivatives in the phylogenetic tree of $r b c \mathrm{~L}$ gene of the cpDNA confirms each of the parents as the evolution origin of the mutant lines. Differentiation of IB-CR into cluster I and the mutant lines IT-719G400MS and IT89KD-400UF into cluster IV appears to correlate with deep green crinkled leaf morphology of IB-CR and deep green normal leaves of IT-719G400MS and IT89KD-400UF. These may suggest that the mutations had caused major changes in the $r b c L$ gene of these cowpea lines. However, the sequence data could not separate the each of the parental lines from their mutant derivatives; this seems justified because each of the parents and their mutants are components within the single Vigna unguiculata entity. This observation indicates that the phenotypic traits of most of the cowpea mutant lines are controlled by nuclear genes that could not be differentiated by the $r b c \mathrm{~L}$ marker. Nevertheless, $r b c \mathrm{~L}$ primer has been used in this study to reveal genetic diversity which exists in the chloroplast genome of selected cowpea mutants and their parents. The findings also showed the changes that occurred at the nucleotide level to produce new mutant varieties of cowpea thus indicating new alleles being added to cowpea genepool. 


\section{Conclusion}

Induced mutation is a valuable tool for creating new genetic variability to complement existing germplasm and broaden crop genetic base. Therefore, creating genetic diversity is needful for effective plant breeding programs. The present study proved that SSR markers are useful for the genetic diversity assessment and characterization of cowpea mutants. Most of the mutants studied were genetically diverse from their parents indicating that they are valuable genetic resources to be added to cowpea genepool. Although the sequence analysis of cpDNA could not reveal details of the mutations with respect to the mutants' morphological characters, however it shows that $r b c L$ markers may be used for phylogenetic and evolutionary studies of mutant lines. Therefore, there is the need for whole genome sequencing of these mutant lines in order to obtain detail information about the genes responsible for the mutants' phenotypes and how they may enhance the genetic map and cultivar improvement of cowpea.

\section{Acknowledgements}

We thank Dr. Wole Oyatomi of the Genetic Resources Centre of International Institute of Tropical Agriculture for the SSR primers used in this study.

\section{Conflicts of Interest}

The authors declare that the research was conducted in the absence of any commercial or financial relationships that could be construed as a potential conflict of interest.

\section{References}

[1] Bennici, A., Maria, A. and Giovanni, G.V. (2003) Genetic Stability and Uniformity of Foeniculum vulgare Mill. Regenerated Plants through Organogenesis and Somatic Embryogenesis. Plant Science, 161, 221-227.

[2] Hamzekhanlu, M., Izadi-Darbandi, A., Pirvali-Beiranvand, N., Teher-Halljian, M. and Majdabadi, A. (2011) Phenotypic and Molecular Analysis of $\mathrm{M}_{7}$ Generation of Soybean Mutant Lines through Random Amplified Polymorphic DNA (RAPD) Marker and Some Morphological Traits. African Journal of Agricultural Research, 6, 1779-1785.

[3] Shiran, B., Amirbakhtiar, N., Kiani, S., Mohammadi, S.H., Sayed-Tabatabaei, B.E. and Moradi, H. (2007) Molecular Characterization and Genetic Relationship among Almond Cultivars Assessed by RAPD and SSR Markers. Scientia Horticulturae, 111, 280-290. https://doi.org/10.1016/j.scienta.2006.10.024

[4] Khan, T., Reza, O.H., Khan, A., Hoque, S., Islam, S. and Khan, B. (2015) Genetic Diversity Analysis of Cowpea by RAPD Markers. International Journal of Innovation and Applied Studies, 10, 459-465.

[5] Meglic, V. and Staub, J.E. (1996) Inheritance and Linkage Relationships of Isozyme and Morphological Loci in Cucumber (Cucumis sativus L.). Theoretical and Applied Genetics, 92, 865-872. https://doi.org/10.1007/BF00221899

[6] Tan, H., Tie, M., Luo, Q., Zhu, Y., Lai, J. and Li, H. (2012) A Review of Molecular Markers Applied in Cowpea (Vigna unguiculata L. Walp.) Breeding. Journal of Life 
Sciences, 6, 1190-1199.

[7] Udensi, O.U., Okon, E., Ikpeme, E.V., Onung, O.O. and Ogban, F.U, (2015) Assessing Genetic Diversity in Cowpea (Vigna unguiculata L. Walp.) Accessions Obtained from IITA, Nigeria Using Random Amplified Polymorphic DNA (RAPD) International Journal of Plant Breeding and Genetics, 10, 12-22.

https://doi.org/10.3923/ijpbg.2016.12.22

[8] Brown, S.M., Hopkins, M.S., Mitchell, S.E., Senior, M.L., Wang, T.Y., Duncan, R.R., Gonzalez-Candelas, F. and Kresovich, S. (1996) Multiple Methods for the Identification of Polymorphic Simple Sequence Repeats (SSRs) in Sorghum [Sorghum bicolor (L.) Moench]. Theoretical and Applied Genetics, 93, 190-198.

https://doi.org/10.1007/BF00225745

[9] Kolade, O.A., Olowolafe, M.O. and Fawole, I. (2016) Characterization of Mutant Cowpea [Vigna unguiculata (L) Walp] Lines Using Random Amplified Polymorphic DNAs (RAPDs) and Amplified Fragment Length Polymorphism (AFLP) Markers. African Journal of Biotechnology, 15, 2530-2537. https://doi.org/10.5897/AJB2015.14539

[10] Ali, Z.B., Yao, K.N., Odeny, D.A., Kyalo, M., Skilton, R. and Eltahir, I.M. (2015) Assessing the Genetic Diversity of Cowpea [Vigna unguiculata (L.) Walp.] Accessions from Sudan Using Simple Sequence Repeat (SSR) Markers. African Journal of Plant Science, 9, 293-304. https://doi.org/10.5897/AJPS2015.1313

[11] Asare, A.T., Gowda, B.S., Galyuon, K.A., Aboagye, L.L., Takrama, J.F. and Timko, M.P. (2010) Assessment of the Genetic Diversity in Cowpea (Vigna unguiculata L. Walp.) Germplasm from Ghana Using Simple Sequence Repeat Markers. Plant Genetic Resources, 8, 142-150. https://doi.org/10.1017/S1479262110000092

[12] Badiane, F.A., Gowda, B.S., Cisse, N., Diouf, D., Sadio, O. and Timko, M.P. (2012) Genetic Relationship of Cowpea (Vigna unguiculata) Varieties from Senegal Based on SSR Markers. Genetics and Molecular Research, 11, 292-304. https://doi.org/10.4238/2012.February.8.4

[13] Lee, J.R., Back, H.J., Yoon, M.S., Park, S.K., Cho, Y.H. and Kim, C.Y. (2009) Analysis of Genetic Diversity of Cowpea Landraces from Korea Determined by Simple Sequence Repeats and Establishment of a Core Collection. Korean Journal of Breeding Science, 41, 369-376.

[14] Li, C.D., Fatokun, C.A., Ubi, B., Singh, B.B. and Scoles, G.J. (2001) Determining Genetic Similarities and Relationships among Cowpea Breeding Lines and Cultivars by Microsatellite Markers. Crop Science, 41, 189-197. https://doi.org/10.2135/cropsci2001.411189x

[15] Ogunkanmi, L.A., Ogundipe, O.T., Ng, N.Q. and Fatokun, C.A. (2008) Genetic Diversity in Wild Relatives of Cowpea (Vigna unguiculata) as Revealed by Simple Sequence Repeats (SSR) Markers. Journal of Food, Agriculture \& Environment, 6, 263-268.

[16] Powell, W., Morgante, M., Andre, C., Hanafey, M., Vogel, J., Tingey, S. and Rafalski, A. (1996) Thecomparison of RFLP, RAPD, AFLP and SSR (Microsatellite) Markers for Germplasm Analysis. Molecular Breeding, 2, 225-238. https://doi.org/10.1007/BF00564200

[17] Barkley, N.A., Dean, R.E., Pittman, R.N., Wang, M.L., Holbrook, C.C. and Pedrson, G.A. (2007) Genetic Diversity of Cultivated and Wild-Type Peanuts Evaluated with M13-Tailed SSR Markers and Sequencing. Genetic Research, 89, 93-106. https://doi.org/10.1017/S0016672307008695

[18] Gioi, T.D., Boora, K.S. and Chaudhary, K. (2012) Identification and Characteriza- 
tion of SSR Markers Linked to Yellow Mosaic Resistance Gene(s) in Cowpea (Vigna unguiculata). International Journal of Plant Research, 2, 1-8. https://doi.org/10.5923/j.plant.20120201.01

[19] Gupta, S.K. and Gopalakrishna, T. (2010) Development of Unigene-Derived SSR Markers in Cowpea (Vigna unguiculata) and Their Transferability to Other Vigna Species. Genome, 53, 508-523. https://doi.org/10.1139/G10-028

[20] Kongjaimun, A., Kaga, A., Tomooka, N., Somta, P., Shimizu, T., Shu, Y., Isemura, T., Vaughan, D.A. and Srinives, P. (2012) An SSR-Based Linkage Map of Yardlong Bean (Vigna unguiculata (L.) Walp. Subsp. Unguiculata Sesquipedalis Group) and QTL Analysis of Pod Length. Genome, 55, 81-92. https://doi.org/10.1139/g11-078

[21] Chase, M.W., Soltis, D.E., Olmstead, R.G., Morgan, D., Les, D.H., Mishler, B.D., Duvall, M.R., Price, R.A., Hills, H.G., Qiu, Y.L., Kron, K.A., Rettig, J.H., Conti, E., Palmer, J.D., Manhart, J.R., Sytsma, K.J., Michaels, H.J., Kress, W.J., Karol, K.G., Clark, W.D., Hedren, M., Gaut, B.S., Jansen, R.K., Kim, K.J., Wimpee, C.F., Smith, J.F., Furnier, G.R., Strauss, S.H., Xiang, Q.Y., Plunkett, G.M., Soltis, P.S., Swensen, S.M., Williams, S.E., Gadek, P.A., Quinn, C.J., Eguiarte, L.E., Golenberg, E., Learn Jr,, G.H., Graham, S.W., Barrett, S.C., Dayanandan, S. and Albert, V.A. (1993) Phylogenetics of Seed Plants: An Analysis of Nucleotide Sequences from the Plastid Gene rbcL. Annals of the Missouri Botanical Garden, 80, 528-580. https://doi.org/10.2307/2399846

[22] Gielly, L. and Taberlet, P. (1994) The Use of Chloroplast DNA to Resolve Plant Phylogeies: Noncoding versus rbcL Sequences. Molecular Biology and Evolution, 11, 769-777.

[23] Palmer, J.D., Jansen, R.K., Michaels, H.J., Chase, M.W. and Manhart, J.R. (1988) Chloroplast DNA Variation and Plant Phylogeny. Annals of the Missouri Botanical Garden, 75, 1180-1206. https://doi.org/10.2307/2399279

[24] Savolainen, D., Chase, M.W., Hoot, S.B., Morton, C.M., Soltis, D.E., Bayer, C., Fay, M.F. and de Bruijn, A.Y. (2000) Phylogenetics of Flowering Plants Based on Combined Analysis of Plastid atpB and $r b c L$ Gene Sequences. Systematic Biology, 49, 306-316. https://doi.org/10.1093/sysbio/49.2.306

[25] Taberlet, P., Gielly, L., Pautou, G. and Boucet, J. (1991) Universal Primers for Amplification of Three Non-Coding Regions of Chlororplast DNA. Plant Molecular Biology, 17, 1105-1109. https://doi.org/10.1007/BF00037152

[26] Chiang, T., Schaal, B.A. and Peng, C. (1998) Universal Primers for Amplification and Sequencing between the atpB and $r b c \mathrm{~L}$ Genes of Chloroplast DNA. Botanical Bulletin of Academia Sinica, 39, 245-250.

[27] Olasupo, F.O., Ilori, C.O., Forster, B.P. and Bado, S. (2016) Mutagenic Effects of Gamma Radiation on Eight Accessions of Cowpea (Vigna unguiculata [L] Walp.).

American Journal of Plant Sciences, 7, 339-351.

https://doi.org/10.4236/ajps.2016.72034

[28] Olasupo, F.O., Ilori, C.O., Forster, B.P. and Bado, S. (2018) Selection for Novel Mutations Induced by Gamma Irradiation in Cowpea (Vigna unguiculata [L] Walp.). International Journal of Plant Breeding and Genetics, 12, 1-12. https://doi.org/10.3923/ijpbg.2018.1.12

[29] Olasupo, F.O., Ilori, C.O. and Muyiwa, A.A. (2016) Radio-Sensitivity of Cowpea to Ultra-Violet Radiation by Pollen Treatment. Journal of Plant Breeding and Crop Science, 8, 339-351. https://doi.org/10.5897/JPBCS2016.0602

[30] Dellaporta, S.L., Wood, J. and Hick, J.B. (1983) A Plant DNA Minipreparation: Version II. Plant Molecular Biology Reporter, 1, 19-21. 
https://doi.org/10.1007/BF02712670

[31] Barril, P. and Nates, S. (2012) Introduction to Agarose and Polyacrylamide Gel Electrophoresis Matrices with Respect to Their Detection Sensitivities. In: Magdeldin, S., Ed., Gel Electrophoresis-Principles and Basics, InTech, London, 4-6.

[32] Albright, L.M. and Slatko, B.E. (2001) Denaturing Polyacrylamide Gel Electrophoresis. Current Protocols in Nucleic Acid Chemistry.

[33] Weir, B.S. (1996) Genetic Data Analysis II. 2nd Edition, Sinauer Associates, Sunderland, 377.

[34] Perrier, X., Flori, A. and Bonnot, F. (2003) Methods for Data Analysis. In: Hamon, P., Seguin, M., Perrier, X. and Glazmann, J.C., Eds., Genetic Diversity of Cultivated Tropical Plants, Science Publisher Inc. and Cirad, Montpellier, 31-63.

[35] Perrier, X. and Jacquemoud-Collet, J.P. (2006) DARwin Software. http://darwin.cirad.fr/darwin

[36] Tamura, K., Peterson, D., Peterson, N., Stecher, G., Nei, M. and Kumar, S. (2011) MEGA5: Molecular Evolutionary Genetics Analysis Using Maximum Likelihood, Evolutionary Distance, and Maximum Parsimony Methods. Molecular Biology and Evolution, 28, 2731-2739. https://doi.org/10.1093/molbev/msr121

[37] Sneath, P.H.A. and Sokal, R.R. (1973) Numerical Taxonomy.

[38] Felsenstein, J. (1985) Confidence Limits on Phylogenies: An Approach Using the Bootstrap. Evolution, 39, 783-791. https://doi.org/10.1111/j.1558-5646.1985.tb00420.x

[39] Kimura, M. (1980) A Simple Method for Estimating Evolutionary Rate of Base Substitutions through Comparative Studies of Nucleotide Sequences. Journal of Molecular Evolution, 16, 111-120. https://doi.org/10.1007/BF01731581

[40] Lee, S., Costanzo, S. and Jia, Y. (2012) The Structure and Regulation of Genes and Consequences of Genetic Mutations. In: Shu, Q.Y., Forster, B.P. and Nakagawa, H., Eds., Plant Mutation Breeding and Biotechnology. Plant Breeding and Genetics Section, Joint FAO/IAEA Division of Nuclear Techniques in Food and Agriculture International Atomic Energy Agency, Vienna, 31-45.

[41] Brown, N. (2013) Mutagenesis. Institution of Plant Breeding, Genetics and Genomics, University of Georgia, Athens. http://plantbreeding.coe.uga.edu/index.php?title=20._Mutagenesis

[42] Yamane, K., Yano, K. and Kawahara, T. (2006) Pattern and Rate of Indel Evolution Inferred from Whole Chloroplast Intergenic Regions in Sugarcane, Maize and Rice. DNA Research, 13, 197-204. https://doi.org/10.1093/dnares/dsl012 


\section{Supplementary}

Table S1. Estimated genetic divergence among the sequences of cowpea obtained using $r b c L$ gene.

\begin{tabular}{|c|c|c|c|}
\hline Genotype 1 & Genotype 2 & Distance & Standard error \\
\hline IB-LT & IT89KD-NL & 0.008 & 0.008 \\
\hline IB-LT & IT90K-BS-1 & 0.008 & 0.008 \\
\hline IT89KD-NL & IT90K-BS-1 & 0.016 & 0.011 \\
\hline IB-LT & IB-ER & 0.000 & 0.000 \\
\hline IT89KD-NL & IB-ER & 0.008 & 0.008 \\
\hline IT90K-BS-1 & IB-ER & 0.008 & 0.008 \\
\hline IB-LT & IB-Y-2 & 0.016 & 0.011 \\
\hline IT89KD-NL & IB-Y-2 & 0.016 & 0.011 \\
\hline IT90K-BS-1 & IB-Y-2 & 0.024 & 0.014 \\
\hline IB-ER & IB-Y-2 & 0.016 & 0.011 \\
\hline IB-LT & IT86D-719 & 0.008 & 0.008 \\
\hline IT89KD-NL & IT86D-719 & 0.008 & 0.008 \\
\hline IT90K-BS-1 & IT86D-719 & 0.016 & 0.012 \\
\hline IB-ER & IT86D-719 & 0.008 & 0.008 \\
\hline IB-Y-2 & IT86D-719 & 0.016 & 0.011 \\
\hline IB-LT & IT-719FPL & 0.000 & 0.000 \\
\hline IT89KD-NL & IT-719FPL & 0.000 & 0.000 \\
\hline IT90K-BS-1 & IT-719FPL & 0.008 & 0.008 \\
\hline IB-ER & IT-719FPL & 0.000 & 0.000 \\
\hline IB-Y-2 & IT-719FPL & 0.008 & 0.008 \\
\hline IT86D-719 & IT-719FPL & 0.008 & 0.008 \\
\hline IB-LT & IT-719G100DW & 0.000 & 0.000 \\
\hline IT89KD-NL & IT-719G100DW & 0.000 & 0.000 \\
\hline IT90K-BS-1 & IT-719G100DW & 0.008 & 0.008 \\
\hline IB-ER & IT-719G100DW & 0.000 & 0.000 \\
\hline IB-Y-2 & IT-719G100DW & 0.008 & 0.008 \\
\hline IT86D-719 & IT-719G100DW & 0.008 & 0.008 \\
\hline IT-719FPL & IT-719G100DW & 0.000 & 0.000 \\
\hline IB-LT & IT89KD-G400UF & 0.057 & 0.021 \\
\hline IT89KD-NL & IT89KD-G400UF & 0.056 & 0.021 \\
\hline IT90K-BS-1 & IT89KD-G400UF & 0.065 & 0.022 \\
\hline IB-ER & IT89KD-G400UF & 0.056 & 0.021 \\
\hline IB-Y-2 & IT89KD-G400UF & 0.065 & 0.022 \\
\hline IT86D-719 & IT89KD-G400UF & 0.048 & 0.020 \\
\hline IT-719FPL & IT89KD-G400UF & 0.056 & 0.021 \\
\hline IT-719G100DW & IT89KD-G400UF & 0.056 & 0.021 \\
\hline IB-LT & IT90K-BS-3 & 0.016 & 0.011 \\
\hline IT89KD-NL & IT90K-BS-3 & 0.016 & 0.011 \\
\hline
\end{tabular}




\section{Continued}

\begin{tabular}{|c|c|c|c|}
\hline IT90K-BS-1 & IT90K-BS-3 & 0.008 & 0.008 \\
\hline IB-ER & IT90K-BS-3 & 0.016 & 0.011 \\
\hline IB-Y-2 & IT90K-BS-3 & 0.008 & 0.008 \\
\hline IT86D-719 & IT90K-BS-3 & 0.024 & 0.014 \\
\hline IT-719FPL & IT90K-BS-3 & 0.016 & 0.011 \\
\hline IT-719G100DW & IT90K-BS-3 & 0.016 & 0.011 \\
\hline IT89KD-G400UF & IT90K-BS-3 & 0.073 & 0.024 \\
\hline IB-LT & IT90K500-EM & 0.008 & 0.008 \\
\hline IT89KD-NL & IT90K500-EM & 0.008 & 0.008 \\
\hline IT90K-BS-1 & IT90K500-EM & 0.016 & 0.012 \\
\hline IB-ER & IT90K500-EM & 0.008 & 0.008 \\
\hline IB-Y-2 & IT90K500-EM & 0.016 & 0.011 \\
\hline IT86D-719 & IT90K500-EM & 0.008 & 0.008 \\
\hline IT-719FPL & IT90K500-EM & 0.008 & 0.008 \\
\hline IT-719G100DW & IT90K500-EM & 0.008 & 0.008 \\
\hline IT89KD-G400UF & IT90K500-EM & 0.056 & 0.021 \\
\hline IT90K-BS-3 & IT90K500-EM & 0.032 & 0.016 \\
\hline IB-LT & IB-CR & 0.016 & 0.011 \\
\hline IT89KD-NL & IB-CR & 0.016 & 0.011 \\
\hline IT90K-BS-1 & IB-CR & 0.008 & 0.008 \\
\hline IB-ER & IB-CR & 0.016 & 0.011 \\
\hline IB-Y-2 & IB-CR & 0.008 & 0.008 \\
\hline IT86D-719 & IB-CR & 0.024 & 0.014 \\
\hline IT-719FPL & IB-CR & 0.016 & 0.011 \\
\hline IT-719G100DW & IB-CR & 0.016 & 0.011 \\
\hline IT89KD-G400UF & IB-CR & 0.073 & 0.024 \\
\hline IT90K-BS-3 & IB-CR & 0.000 & 0.000 \\
\hline IT90K500-EM & IB-CR & 0.032 & 0.016 \\
\hline IB-LT & IT-719Y & 0.008 & 0.008 \\
\hline IT89KD-NL & IT-719Y & 0.008 & 0.008 \\
\hline IT90K-BS-1 & IT-719Y & 0.008 & 0.008 \\
\hline IB-ER & IT-719Y & 0.008 & 0.008 \\
\hline IB-Y-2 & IT-719Y & 0.000 & 0.000 \\
\hline IT86D-719 & IT-719Y & 0.016 & 0.011 \\
\hline IT-719FPL & IT-719Y & 0.008 & 0.008 \\
\hline IT-719G100DW & IT-719Y & 0.008 & 0.008 \\
\hline IT89KD-G400UF & IT-719Y & 0.065 & 0.023 \\
\hline IT90K-BS-3 & IT-719Y & 0.000 & 0.000 \\
\hline IT90K500-EM & IT-719Y & 0.016 & 0.011 \\
\hline IB-CR & IT-719Y & 0.000 & 0.000 \\
\hline
\end{tabular}




\section{Continued}

\begin{tabular}{|c|c|c|c|}
\hline IB-LT & IT-719BN-1 & 0.008 & 0.008 \\
\hline IT89KD-NL & IT-719BN-1 & 0.008 & 0.008 \\
\hline IT90K-BS-1 & IT-719BN-1 & 0.008 & 0.008 \\
\hline IB-ER & IT-719BN-1 & 0.008 & 0.008 \\
\hline IB-Y-2 & IT-719BN-1 & 0.016 & 0.012 \\
\hline IT86D-719 & IT-719BN-1 & 0.000 & 0.000 \\
\hline IT-719FPL & IT-719BN-1 & 0.008 & 0.008 \\
\hline IT-719G100DW & IT-719BN-1 & 0.008 & 0.008 \\
\hline IT89KD-G400UF & IT-719BN-1 & 0.049 & 0.020 \\
\hline IT90K-BS-3 & IT-719BN-1 & 0.016 & 0.012 \\
\hline IT90K500-EM & IT-719BN-1 & 0.008 & 0.008 \\
\hline IB-CR & IT-719BN-1 & 0.016 & 0.012 \\
\hline IT-719Y & IT-719BN-1 & 0.016 & 0.012 \\
\hline IB-LT & IT-719BN-2 & 0.016 & 0.012 \\
\hline IT89KD-NL & IT-719BN-2 & 0.016 & 0.011 \\
\hline IT90K-BS-1 & IT-719BN-2 & 0.016 & 0.011 \\
\hline IB-ER & IT-719BN-2 & 0.016 & 0.011 \\
\hline IB-Y-2 & IT-719BN-2 & 0.016 & 0.011 \\
\hline IT86D-719 & IT-719BN-2 & 0.024 & 0.014 \\
\hline IT-719FPL & IT-719BN-2 & 0.016 & 0.011 \\
\hline IT-719G100DW & IT-719BN-2 & 0.016 & 0.011 \\
\hline IT89KD-G400UF & IT-719BN-2 & 0.065 & 0.023 \\
\hline IT90K-BS-3 & IT-719BN-2 & 0.016 & 0.011 \\
\hline IT90K500-EM & IT-719BN-2 & 0.024 & 0.014 \\
\hline IB-CR & IT-719BN-2 & 0.016 & 0.011 \\
\hline IT-719Y & IT-719BN-2 & 0.016 & 0.011 \\
\hline IT-719BN-1 & IT-719BN-2 & 0.025 & 0.014 \\
\hline IB-LT & IB & 0.008 & 0.008 \\
\hline IT89KD-NL & IB & 0.008 & 0.008 \\
\hline IT90K-BS-1 & IB & 0.008 & 0.008 \\
\hline IB-ER & IB & 0.008 & 0.008 \\
\hline IB-Y-2 & IB & 0.000 & 0.000 \\
\hline IT86D-719 & IB & 0.016 & 0.011 \\
\hline IT-719FPL & IB & 0.008 & 0.008 \\
\hline IT-719G100DW & IB & 0.008 & 0.008 \\
\hline IT89KD-G400UF & IB & 0.065 & 0.023 \\
\hline IT90K-BS-3 & IB & 0.000 & 0.000 \\
\hline IT90K500-EM & IB & 0.016 & 0.011 \\
\hline IB-CR & IB & 0.000 & 0.000 \\
\hline IT-719Y & IB & 0.000 & 0.000 \\
\hline
\end{tabular}




\section{Continued}

\begin{tabular}{|c|c|c|c|}
\hline IT-719BN-1 & IB & 0.016 & 0.012 \\
\hline IT-719BN-2 & IB & 0.016 & 0.011 \\
\hline IB-LT & IT90K-284TRV & 0.000 & 0.000 \\
\hline IT89KD-NL & IT90K-284TRV & 0.000 & 0.000 \\
\hline IT90K-BS-1 & IT90K-284TRV & 0.000 & 0.000 \\
\hline IB-ER & IT90K-284TRV & 0.000 & 0.000 \\
\hline IB-Y-2 & IT90K-284TRV & 0.008 & 0.008 \\
\hline IT86D-719 & IT90K-284TRV & 0.008 & 0.008 \\
\hline IT-719FPL & IT90K-284TRV & 0.000 & 0.000 \\
\hline IT-719G100DW & IT90K-284TRV & 0.000 & 0.000 \\
\hline IT89KD-G400UF & IT90K-284TRV & 0.057 & 0.021 \\
\hline IT90K-BS-3 & IT90K-284TRV & 0.016 & 0.011 \\
\hline IT90K500-EM & IT90K-284TRV & 0.008 & 0.008 \\
\hline IB-CR & IT90K-284TRV & 0.016 & 0.011 \\
\hline IT-719Y & IT90K-284TRV & 0.008 & 0.008 \\
\hline IT-719BN-1 & IT90K-284TRV & 0.008 & 0.008 \\
\hline IT-719BN-2 & IT90K-284TRV & 0.016 & 0.011 \\
\hline IB & IT90K-284TRV & 0.008 & 0.008 \\
\hline IB-LT & IT90K-BS-4 & 0.008 & 0.008 \\
\hline IT89KD-NL & IT90K-BS-4 & 0.008 & 0.008 \\
\hline IT90K-BS-1 & IT90K-BS-4 & 0.008 & 0.008 \\
\hline IB-ER & IT90K-BS-4 & 0.008 & 0.008 \\
\hline IB-Y-2 & IT90K-BS-4 & 0.000 & 0.000 \\
\hline IT86D-719 & IT90K-BS-4 & 0.016 & 0.011 \\
\hline IT-719FPL & IT90K-BS-4 & 0.008 & 0.008 \\
\hline IT-719G100DW & IT90K-BS-4 & 0.008 & 0.008 \\
\hline IT89KD-G400UF & IT90K-BS-4 & 0.065 & 0.023 \\
\hline IT90K-BS-3 & IT90K-BS-4 & 0.000 & 0.000 \\
\hline IT90K500-EM & IT90K-BS-4 & 0.016 & 0.011 \\
\hline IB-CR & IT90K-BS-4 & 0.000 & 0.000 \\
\hline IT-719Y & IT90K-BS-4 & 0.000 & 0.000 \\
\hline IT-719BN-1 & IT90K-BS-4 & 0.016 & 0.012 \\
\hline IT-719BN-2 & IT90K-BS-4 & 0.016 & 0.011 \\
\hline IB & IT90K-BS-4 & 0.000 & 0.000 \\
\hline IT90K-284TRV & IT90K-BS-4 & 0.008 & 0.008 \\
\hline IB-LT & IB-Y-1 & 0.008 & 0.008 \\
\hline IT89KD-NL & IB-Y-1 & 0.008 & 0.008 \\
\hline IT90K-BS-1 & IB-Y-1 & 0.008 & 0.008 \\
\hline IB-ER & IB-Y-1 & 0.008 & 0.008 \\
\hline IB-Y-2 & IB-Y-1 & 0.000 & 0.000 \\
\hline IT86D-719 & IB-Y-1 & 0.016 & 0.011 \\
\hline
\end{tabular}




\section{Continued}

\begin{tabular}{|c|c|c|c|}
\hline IT-719FPL & IB-Y-1 & 0.008 & 0.008 \\
\hline IT-719G100DW & IB-Y-1 & 0.008 & 0.008 \\
\hline IT89KD-G400UF & IB-Y-1 & 0.065 & 0.023 \\
\hline IT90K-BS-3 & IB-Y-1 & 0.000 & 0.000 \\
\hline IT90K500-EM & IB-Y-1 & 0.016 & 0.011 \\
\hline IB-CR & IB-Y-1 & 0.000 & 0.000 \\
\hline IT-719Y & IB-Y-1 & 0.000 & 0.000 \\
\hline IT-719BN-1 & IB-Y-1 & 0.016 & 0.012 \\
\hline IT-719BN-2 & IB-Y-1 & 0.016 & 0.011 \\
\hline IB & IB-Y-1 & 0.000 & 0.000 \\
\hline IT90K-284TRV & IB-Y-1 & 0.008 & 0.008 \\
\hline IT90K-BS-4 & IB-Y-1 & 0.000 & 0.000 \\
\hline IB-LT & IT-719G200BT & 0.008 & 0.008 \\
\hline IT89KD-NL & IT-719G200BT & 0.008 & 0.008 \\
\hline IT90K-BS-1 & IT-719G200BT & 0.008 & 0.008 \\
\hline IB-ER & IT-719G200BT & 0.008 & 0.008 \\
\hline IB-Y-2 & IT-719G200BT & 0.008 & 0.008 \\
\hline IT86D-719 & IT-719G200BT & 0.000 & 0.000 \\
\hline IT-719FPL & IT-719G200BT & 0.008 & 0.008 \\
\hline IT-719G100DW & IT-719G200BT & 0.008 & 0.008 \\
\hline IT89KD-G400UF & IT-719G200BT & 0.050 & 0.020 \\
\hline IT90K-BS-3 & IT-719G200BT & 0.008 & 0.008 \\
\hline IT90K500-EM & IT-719G200BT & 0.008 & 0.008 \\
\hline IB-CR & IT-719G200BT & 0.008 & 0.008 \\
\hline IT-719Y & IT-719G200BT & 0.008 & 0.008 \\
\hline IT-719BN-1 & IT-719G200BT & 0.000 & 0.000 \\
\hline IT-719BN-2 & IT-719G200BT & 0.017 & 0.012 \\
\hline IB & IT-719G200BT & 0.008 & 0.008 \\
\hline IT90K-284TRV & IT-719G200BT & 0.008 & 0.008 \\
\hline IT90K-BS-4 & IT-719G200BT & 0.008 & 0.008 \\
\hline IB-Y-1 & IT-719G200BT & 0.008 & 0.008 \\
\hline IB-LT & IT-719G400MS & 0.041 & 0.018 \\
\hline IT89KD-NL & IT-719G400MS & 0.041 & 0.018 \\
\hline IT90K-BS-1 & IT-719G400MS & 0.041 & 0.018 \\
\hline IB-ER & IT-719G400MS & 0.041 & 0.018 \\
\hline IB-Y-2 & IT-719G400MS & 0.041 & 0.018 \\
\hline IT86D-719 & IT-719G400MS & 0.033 & 0.016 \\
\hline IT-719FPL & IT-719G400MS & 0.041 & 0.018 \\
\hline IT-719G100DW & IT-719G400MS & 0.049 & 0.019 \\
\hline IT89KD-G400UF & IT-719G400MS & 0.041 & 0.019 \\
\hline
\end{tabular}




\section{Continued}

\begin{tabular}{|c|c|c|c|}
\hline IT90K-BS-3 & IT-719G400MS & 0.056 & 0.020 \\
\hline IT90K500-EM & IT-719G400MS & 0.056 & 0.020 \\
\hline IB-CR & IT-719G400MS & 0.056 & 0.020 \\
\hline IT-719Y & IT-719G400MS & 0.041 & 0.018 \\
\hline IT-719BN-1 & IT-719G400MS & 0.033 & 0.016 \\
\hline IT-719BN-2 & IT-719G400MS & 0.041 & 0.018 \\
\hline IB & IT-719G400MS & 0.049 & 0.019 \\
\hline IT90K-284TRV & IT-719G400MS & 0.056 & 0.020 \\
\hline IT90K-BS-4 & IT-719G400MS & 0.041 & 0.018 \\
\hline IB-Y-1 & IT-719G400MS & 0.041 & 0.018 \\
\hline IT-719G200BT & IT-719G400MS & 0.033 & 0.016 \\
\hline IB-LT & IT89KD-G400HT & 0.000 & 0.000 \\
\hline IT89KD-NL & IT89KD-G400HT & 0.000 & 0.000 \\
\hline IT90K-BS-1 & IT89KD-G400HT & 0.000 & 0.000 \\
\hline IB-ER & IT89KD-G400HT & 0.000 & 0.000 \\
\hline IB-Y-2 & IT89KD-G400HT & 0.000 & 0.000 \\
\hline IT86D-719 & IT89KD-G400HT & 0.008 & 0.008 \\
\hline IT-719FPL & IT89KD-G400HT & 0.000 & 0.000 \\
\hline IT-719G100DW & IT89KD-G400HT & 0.000 & 0.000 \\
\hline IT89KD-G400UF & IT89KD-G400HT & 0.057 & 0.021 \\
\hline IT90K-BS-3 & IT89KD-G400HT & 0.000 & 0.000 \\
\hline IT90K500-EM & IT89KD-G400HT & 0.008 & 0.008 \\
\hline IB-CR & IT89KD-G400HT & 0.000 & 0.000 \\
\hline IT-719Y & IT89KD-G400HT & 0.000 & 0.000 \\
\hline IT-719BN-1 & IT89KD-G400HT & 0.008 & 0.008 \\
\hline IT-719BN-2 & IT89KD-G400HT & 0.008 & 0.008 \\
\hline IB & IT89KD-G400HT & 0.000 & 0.000 \\
\hline IT90K-284TRV & IT89KD-G400HT & 0.000 & 0.000 \\
\hline IT90K-BS-4 & IT89KD-G400HT & 0.000 & 0.000 \\
\hline IB-Y-1 & IT89KD-G400HT & 0.000 & 0.000 \\
\hline IT-719G200BT & IT89KD-G400HT & 0.008 & 0.008 \\
\hline IT-719G400MS & IT89KD-G400HT & 0.041 & 0.018 \\
\hline IB-LT & IT90K-284-2 & 0.000 & 0.000 \\
\hline IT89KD-NL & IT90K-284-2 & 0.000 & 0.000 \\
\hline IT90K-BS-1 & IT90K-284-2 & 0.000 & 0.000 \\
\hline IB-ER & IT90K-284-2 & 0.000 & 0.000 \\
\hline IB-Y-2 & IT90K-284-2 & 0.000 & 0.000 \\
\hline IT86D-719 & IT90K-284-2 & 0.008 & 0.008 \\
\hline IT-719FPL & IT90K-284-2 & 0.000 & 0.000 \\
\hline IT-719G100DW & IT90K-284-2 & 0.000 & 0.000 \\
\hline
\end{tabular}




\section{Continued}

\begin{tabular}{|c|c|c|c|}
\hline IT89KD-G400UF & IT90K-284-2 & 0.057 & 0.021 \\
\hline IT90K-BS-3 & IT90K-284-2 & 0.000 & 0.000 \\
\hline IT90K500-EM & IT90K-284-2 & 0.008 & 0.008 \\
\hline IB-CR & IT90K-284-2 & 0.000 & 0.000 \\
\hline IT-719Y & IT90K-284-2 & 0.000 & 0.000 \\
\hline IT-719BN-1 & IT90K-284-2 & 0.008 & 0.008 \\
\hline IT-719BN-2 & IT90K-284-2 & 0.008 & 0.008 \\
\hline IB & IT90K-284-2 & 0.000 & 0.000 \\
\hline IT90K-284TRV & IT90K-284-2 & 0.000 & 0.000 \\
\hline IT90K-BS-4 & IT90K-284-2 & 0.000 & 0.000 \\
\hline IB-Y-1 & IT90K-284-2 & 0.000 & 0.000 \\
\hline IT-719G200BT & IT90K-284-2 & 0.008 & 0.008 \\
\hline IT-719G400MS & IT90K-284-2 & 0.041 & 0.018 \\
\hline IT89KD-G400HT & IT90K-284-2 & 0.000 & 0.000 \\
\hline IB-LT & IT90K-284FPL-2 & 0.000 & 0.000 \\
\hline IT89KD-NL & IT90K-284FPL-2 & 0.000 & 0.000 \\
\hline IT90K-BS-1 & IT90K-284FPL-2 & 0.000 & 0.000 \\
\hline IB-ER & IT90K-284FPL-2 & 0.000 & 0.000 \\
\hline IB-Y-2 & IT90K-284FPL-2 & 0.000 & 0.000 \\
\hline IT86D-719 & IT90K-284FPL-2 & 0.008 & 0.008 \\
\hline IT-719FPL & IT90K-284FPL-2 & 0.000 & 0.000 \\
\hline IT-719G100DW & IT90K-284FPL-2 & 0.000 & 0.000 \\
\hline IT89KD-G400UF & IT90K-284FPL-2 & 0.057 & 0.021 \\
\hline IT90K-BS-3 & IT90K-284FPL-2 & 0.008 & 0.008 \\
\hline IT90K500-EM & IT90K-284FPL-2 & 0.016 & 0.011 \\
\hline IB-CR & IT90K-284FPL-2 & 0.008 & 0.008 \\
\hline IT-719Y & IT90K-284FPL-2 & 0.000 & 0.000 \\
\hline IT-719BN-1 & IT90K-284FPL-2 & 0.008 & 0.008 \\
\hline IT-719BN-2 & IT90K-284FPL-2 & 0.008 & 0.008 \\
\hline IB & IT90K-284FPL-2 & 0.000 & 0.000 \\
\hline IT90K-284TRV & IT90K-284FPL-2 & 0.008 & 0.008 \\
\hline IT90K-BS-4 & IT90K-284FPL-2 & 0.000 & 0.000 \\
\hline IB-Y-1 & IT90K-284FPL-2 & 0.000 & 0.000 \\
\hline IT-719G200BT & IT90K-284FPL-2 & 0.008 & 0.008 \\
\hline IT-719G400MS & IT90K-284FPL-2 & 0.048 & 0.019 \\
\hline IT89KD-G400HT & IT90K-284FPL-2 & 0.000 & 0.000 \\
\hline IT90K-284-2 & IT90K-284FPL-2 & 0.000 & 0.000 \\
\hline IB-LT & IT90K-UVFPL-REV & 0.008 & 0.008 \\
\hline IT89KD-NL & IT90K-UVFPL-REV & 0.008 & 0.008 \\
\hline IT90K-BS-1 & IT90K-UVFPL-REV & 0.008 & 0.008 \\
\hline
\end{tabular}




\section{Continued}

\begin{tabular}{|c|c|c|c|}
\hline IB-ER & IT90K-UVFPL-REV & 0.008 & 0.008 \\
\hline IB-Y-2 & IT90K-UVFPL-REV & 0.008 & 0.008 \\
\hline IT86D-719 & IT90K-UVFPL-REV & 0.016 & 0.012 \\
\hline IT-719FPL & IT90K-UVFPL-REV & 0.008 & 0.008 \\
\hline IT-719G100DW & IT90K-UVFPL-REV & 0.008 & 0.008 \\
\hline IT89KD-G400UF & IT90K-UVFPL-REV & 0.066 & 0.023 \\
\hline IT90K-BS-3 & IT90K-UVFPL-REV & 0.008 & 0.008 \\
\hline IT90K500-EM & IT90K-UVFPL-REV & 0.024 & 0.014 \\
\hline IB-CR & IT90K-UVFPL-REV & 0.024 & 0.013 \\
\hline IT-719Y & IT90K-UVFPL-REV & 0.008 & 0.008 \\
\hline IT-719BN-1 & IT90K-UVFPL-REV & 0.017 & 0.012 \\
\hline IT-719BN-2 & IT90K-UVFPL-REV & 0.016 & 0.011 \\
\hline IB & IT90K-UVFPL-REV & 0.008 & 0.008 \\
\hline IT90K-284TRV & IT90K-UVFPL-REV & 0.016 & 0.011 \\
\hline IT90K-BS-4 & IT90K-UVFPL-REV & 0.008 & 0.008 \\
\hline IB-Y-1 & IT90K-UVFPL-REV & 0.008 & 0.008 \\
\hline IT-719G200BT & IT90K-UVFPL-REV & 0.017 & 0.012 \\
\hline IT-719G400MS & IT90K-UVFPL-REV & 0.065 & 0.022 \\
\hline IT89KD-G400HT & IT90K-UVFPL-REV & 0.008 & 0.008 \\
\hline IT90K-284-2 & IT90K-UVFPL-REV & 0.008 & 0.008 \\
\hline IT90K-284FPL-2 & IT90K-UVFPL-REV & 0.016 & 0.011 \\
\hline IB-LT & IT90K-284SP & 0.000 & 0.000 \\
\hline IT89KD-NL & IT90K-284SP & 0.000 & 0.000 \\
\hline IT90K-BS-1 & IT90K-284SP & 0.000 & 0.000 \\
\hline IB-ER & IT90K-284SP & 0.000 & 0.000 \\
\hline IB-Y-2 & IT90K-284SP & 0.000 & 0.000 \\
\hline IT86D-719 & IT90K-284SP & 0.008 & 0.008 \\
\hline IT-719FPL & IT90K-284SP & 0.000 & 0.000 \\
\hline IT-719G100DW & IT90K-284SP & 0.000 & 0.000 \\
\hline IT89KD-G400UF & IT90K-284SP & 0.057 & 0.021 \\
\hline IT90K-BS-3 & IT90K-284SP & 0.000 & 0.000 \\
\hline IT90K500-EM & IT90K-284SP & 0.008 & 0.008 \\
\hline IB-CR & IT90K-284SP & 0.000 & 0.000 \\
\hline IT-719Y & IT90K-284SP & 0.000 & 0.000 \\
\hline IT-719BN-1 & IT90K-284SP & 0.008 & 0.008 \\
\hline IT-719BN-2 & IT90K-284SP & 0.008 & 0.008 \\
\hline IB & IT90K-284SP & 0.000 & 0.000 \\
\hline IT90K-284TRV & IT90K-284SP & 0.000 & 0.000 \\
\hline IT90K-BS-4 & IT90K-284SP & 0.000 & 0.000 \\
\hline IB-Y-1 & IT90K-284SP & 0.000 & 0.000 \\
\hline
\end{tabular}




\section{Continued}

\begin{tabular}{|c|c|c|c|}
\hline IT-719G200BT & IT90K-284SP & 0.008 & 0.008 \\
\hline IT-719G400MS & IT90K-284SP & 0.041 & 0.018 \\
\hline IT89KD-G400HT & IT90K-284SP & 0.000 & 0.000 \\
\hline IT90K-284-2 & IT90K-284SP & 0.000 & 0.000 \\
\hline IT90K-284FPL-2 & IT90K-284SP & 0.000 & 0.000 \\
\hline IT90K-UVFPL-REV & IT90K-284SP & 0.008 & 0.008 \\
\hline IB-LT & IB-ER-2 & 0.000 & 0.000 \\
\hline IT89KD-NL & IB-ER-2 & 0.000 & 0.000 \\
\hline IT90K-BS-1 & IB-ER-2 & 0.000 & 0.000 \\
\hline IB-ER & IB-ER-2 & 0.000 & 0.000 \\
\hline IB-Y-2 & IB-ER-2 & 0.000 & 0.000 \\
\hline IT86D-719 & IB-ER-2 & 0.008 & 0.008 \\
\hline IT-719FPL & IB-ER-2 & 0.000 & 0.000 \\
\hline IT-719G100DW & IB-ER-2 & 0.000 & 0.000 \\
\hline IT89KD-G400UF & IB-ER-2 & 0.057 & 0.021 \\
\hline IT90K-BS-3 & IB-ER-2 & 0.000 & 0.000 \\
\hline IT90K500-EM & IB-ER-2 & 0.008 & 0.008 \\
\hline IB-CR & IB-ER-2 & 0.000 & 0.000 \\
\hline IT-719Y & IB-ER-2 & 0.000 & 0.000 \\
\hline IT-719BN-1 & IB-ER-2 & 0.008 & 0.008 \\
\hline IT-719BN-2 & IB-ER-2 & 0.008 & 0.008 \\
\hline IB & IB-ER-2 & 0.000 & 0.000 \\
\hline IT90K-284TRV & IB-ER-2 & 0.000 & 0.000 \\
\hline IT90K-BS-4 & IB-ER-2 & 0.000 & 0.000 \\
\hline IB-Y-1 & IB-ER-2 & 0.000 & 0.000 \\
\hline IT-719G200BT & IB-ER-2 & 0.008 & 0.008 \\
\hline IT-719G400MS & IB-ER-2 & 0.041 & 0.018 \\
\hline IT89KD-G400HT & IB-ER-2 & 0.000 & 0.000 \\
\hline IT90K-284-2 & IB-ER-2 & 0.000 & 0.000 \\
\hline IT90K-284FPL-2 & IB-ER-2 & 0.000 & 0.000 \\
\hline IT90K-UVFPL-REV & IB-ER-2 & 0.008 & 0.008 \\
\hline IT90K-284SP & IB-ER-2 & 0.000 & 0.000 \\
\hline IB-LT & IB-BPC & 0.000 & 0.000 \\
\hline IT89KD-NL & IB-BPC & 0.000 & 0.000 \\
\hline IT90K-BS-1 & IB-BPC & 0.000 & 0.000 \\
\hline IB-ER & IB-BPC & 0.000 & 0.000 \\
\hline IB-Y-2 & IB-BPC & 0.000 & 0.000 \\
\hline IT86D-719 & IB-BPC & 0.008 & 0.008 \\
\hline IT-719FPL & IB-BPC & 0.000 & 0.000 \\
\hline IT-719G100DW & IB-BPC & 0.000 & 0.000 \\
\hline
\end{tabular}




\section{Continued}

\begin{tabular}{|c|c|c|c|}
\hline IT89KD-G400UF & IB-BPC & 0.057 & 0.021 \\
\hline IT90K-BS-3 & IB-BPC & 0.000 & 0.000 \\
\hline IT90K500-EM & IB-BPC & 0.008 & 0.008 \\
\hline IB-CR & IB-BPC & 0.000 & 0.000 \\
\hline IT-719Y & IB-BPC & 0.000 & 0.000 \\
\hline IT-719BN-1 & IB-BPC & 0.008 & 0.008 \\
\hline IT-719BN-2 & IB-BPC & 0.008 & 0.008 \\
\hline IB & IB-BPC & 0.000 & 0.000 \\
\hline IT90K-284TRV & IB-BPC & 0.000 & 0.000 \\
\hline IT90K-BS-4 & IB-BPC & 0.000 & 0.000 \\
\hline IB-Y-1 & IB-BPC & 0.000 & 0.000 \\
\hline IT-719G200BT & IB-BPC & 0.008 & 0.008 \\
\hline IT-719G400MS & IB-BPC & 0.041 & 0.018 \\
\hline IT89KD-G400HT & IB-BPC & 0.000 & 0.000 \\
\hline IT90K-284-2 & IB-BPC & 0.000 & 0.000 \\
\hline IT90K-284FPL-2 & IB-BPC & 0.000 & 0.000 \\
\hline IT90K-UVFPL-REV & IB-BPC & 0.008 & 0.008 \\
\hline IT90K-284SP & IB-BPC & 0.000 & 0.000 \\
\hline IB-ER-2 & IB-BPC & 0.000 & 0.000 \\
\hline IB-LT & IT89KD-374-57 & 0.000 & 0.000 \\
\hline IT89KD-NL & IT89KD-374-57 & 0.000 & 0.000 \\
\hline IT90K-BS-1 & IT89KD-374-57 & 0.000 & 0.000 \\
\hline IB-ER & IT89KD-374-57 & 0.000 & 0.000 \\
\hline IB-Y-2 & IT89KD-374-57 & 0.000 & 0.000 \\
\hline IT86D-719 & IT89KD-374-57 & 0.008 & 0.008 \\
\hline IT-719FPL & IT89KD-374-57 & 0.000 & 0.000 \\
\hline IT-719G100DW & IT89KD-374-57 & 0.000 & 0.000 \\
\hline IT89KD-G400UF & IT89KD-374-57 & 0.050 & 0.020 \\
\hline IT90K-BS-3 & IT89KD-374-57 & 0.000 & 0.000 \\
\hline IT90K500-EM & IT89KD-374-57 & 0.008 & 0.008 \\
\hline IB-CR & IT89KD-374-57 & 0.000 & 0.000 \\
\hline IT-719Y & IT89KD-374-57 & 0.000 & 0.000 \\
\hline IT-719BN-1 & IT89KD-374-57 & 0.008 & 0.008 \\
\hline IT-719BN-2 & IT89KD-374-57 & 0.000 & 0.000 \\
\hline IB & IT89KD-374-57 & 0.000 & 0.000 \\
\hline IT90K-284TRV & IT89KD-374-57 & 0.000 & 0.000 \\
\hline IT90K-BS-4 & IT89KD-374-57 & 0.000 & 0.000 \\
\hline IB-Y-1 & IT89KD-374-57 & 0.000 & 0.000 \\
\hline IT-719G200BT & IT89KD-374-57 & 0.008 & 0.008 \\
\hline IT-719G400MS & IT89KD-374-57 & 0.033 & 0.016 \\
\hline
\end{tabular}




\section{Continued}

\begin{tabular}{|c|c|c|c|}
\hline IT89KD-G400HT & IT89KD-374-57 & 0.000 & 0.000 \\
\hline IT90K-284-2 & IT89KD-374-57 & 0.000 & 0.000 \\
\hline IT90K-284FPL-2 & IT89KD-374-57 & 0.000 & 0.000 \\
\hline IT90K-UVFPL-REV & IT89KD-374-57 & 0.008 & 0.008 \\
\hline IT90K-284SP & IT89KD-374-57 & 0.000 & 0.000 \\
\hline IB-ER-2 & IT89KD-374-57 & 0.000 & 0.000 \\
\hline IB-BPC & IT89KD-374-57 & 0.000 & 0.000 \\
\hline IB-LT & IT90K-BS-2 & 0.000 & 0.000 \\
\hline IT89KD-NL & IT90K-BS-2 & 0.000 & 0.000 \\
\hline IT90K-BS-1 & IT90K-BS-2 & 0.000 & 0.000 \\
\hline IB-ER & IT90K-BS-2 & 0.000 & 0.000 \\
\hline IB-Y-2 & IT90K-BS-2 & 0.000 & 0.000 \\
\hline IT86D-719 & IT90K-BS-2 & 0.008 & 0.008 \\
\hline IT-719FPL & IT90K-BS-2 & 0.000 & 0.000 \\
\hline IT-719G100DW & IT90K-BS-2 & 0.000 & 0.000 \\
\hline IT89KD-G400UF & IT90K-BS-2 & 0.050 & 0.020 \\
\hline IT90K-BS-3 & IT90K-BS-2 & 0.000 & 0.000 \\
\hline IT90K500-EM & IT90K-BS-2 & 0.008 & 0.008 \\
\hline IB-CR & IT90K-BS-2 & 0.000 & 0.000 \\
\hline IT-719Y & IT90K-BS-2 & 0.000 & 0.000 \\
\hline IT-719BN-1 & IT90K-BS-2 & 0.008 & 0.008 \\
\hline IT-719BN-2 & IT90K-BS-2 & 0.000 & 0.000 \\
\hline IB & IT90K-BS-2 & 0.000 & 0.000 \\
\hline IT90K-284TRV & IT90K-BS-2 & 0.000 & 0.000 \\
\hline IT90K-BS-4 & IT90K-BS-2 & 0.000 & 0.000 \\
\hline IB-Y-1 & IT90K-BS-2 & 0.000 & 0.000 \\
\hline IT-719G200BT & IT90K-BS-2 & 0.008 & 0.008 \\
\hline IT-719G400MS & IT90K-BS-2 & 0.041 & 0.018 \\
\hline IT89KD-G400HT & IT90K-BS-2 & 0.000 & 0.000 \\
\hline IT90K-284-2 & IT90K-BS-2 & 0.000 & 0.000 \\
\hline IT90K-284FPL-2 & IT90K-BS-2 & 0.000 & 0.000 \\
\hline IT90K-UVFPL-REV & IT90K-BS-2 & 0.008 & 0.008 \\
\hline IT90K-284SP & IT90K-BS-2 & 0.000 & 0.000 \\
\hline IB-ER-2 & IT90K-BS-2 & 0.000 & 0.000 \\
\hline IB-BPC & IT90K-BS-2 & 0.000 & 0.000 \\
\hline IT89KD-374-57 & IT90K-BS-2 & 0.000 & 0.000 \\
\hline
\end{tabular}

